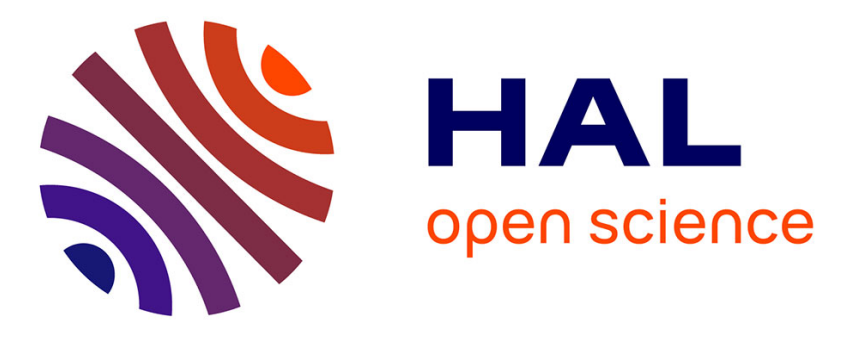

\title{
Mechatronics, Design and Modeling of a Motorcycle Riding Simulator
}

Hichem Arioui, Lamri Nehaoua, Salim Hima, Nicolas Séguy, Stéphane Espié

\section{To cite this version:}

Hichem Arioui, Lamri Nehaoua, Salim Hima, Nicolas Séguy, Stéphane Espié. Mechatronics, Design and Modeling of a Motorcycle Riding Simulator. IEEE/ASME Transactions on Mechatronics, 2010, 15 (5), pp.805 - 818. 10.1109/TMECH.2009.2035499 . hal-00515557

\section{HAL Id: hal-00515557 \\ https://hal.science/hal-00515557}

Submitted on 7 Sep 2010

HAL is a multi-disciplinary open access archive for the deposit and dissemination of scientific research documents, whether they are published or not. The documents may come from teaching and research institutions in France or abroad, or from public or private research centers.
L'archive ouverte pluridisciplinaire HAL, est destinée au dépôt et à la diffusion de documents scientifiques de niveau recherche, publiés ou non, émanant des établissements d'enseignement et de recherche français ou étrangers, des laboratoires publics ou privés. 


\title{
Mechatronics, Design and Modeling of a Motorcycle Riding Simulator
}

\author{
H. Arioui, L. Nehaoua, S. Hima, N. Séguy, and S. Espié
}

\begin{abstract}
This paper describes a new motorcycle riding simulator whose purpose is twofold: (1) it can be used as a training tool for new riders in different scenarios, such as a normal traffic environments or in dangerous riding situations (avoidance, emergency braking, nearly failing or slipping situations and bad weather conditions); and (2) it can be used to study cyclist behavior in such situations and rider-motorcycle interaction.

Our studies have led to the development of an original five degrees-of-freedom (DOF) mechanical platform including double haptic feedback on the handlebar. The remaining components are the basic movements consisting of pitch, roll, and yaw. These components are gathered in a parallel kinematics-type platform to enhance the movement bandwidth of the two-wheeled riding simulator.

Despite its simplicity, the particular appeal of this simulator lies in the possibility of reproducing important motorcycle movements and inertial effects which allow for the perception of sensations close to reality. The motivation behind the choice of platform movements and system actuation are described. Also, theoretical issues (modeling, identification and control aspects) and performance results are provided.
\end{abstract}

Index Terms-Motorcycle, driving simulator, platform mechanics, modeling, identification.

\section{INTRODUCTION}

$\mathbf{T}$ HE increasing use of the motorcycle in recent years is motivated primarily by the increased number of automobile users worldwide. The automobiles create congestion on the roads, increased fuel costs, fewer parking places, and more accidents. Therefore, motorcycles have become a popular solution to these problems, in spite of major issues related mainly to safety.

Undeniably, in the past, the road safety of motorcycles has been marginalized when compared with that of 4-wheeled vehicles, such as trucks and cars. For these classic vehicles, progress has affected all vehicle areas, including safety, comfort, and driving assistance [1], [2]. Safety improvements for motorcycles have tended to lag behind those for 4wheeled vehicles. Motorcycles, however, have not benefited from this technological progress until recently. The result of this negligence is a significant number of motorcycle deaths on the roads [3]. Research institutions have attempted to find solutions for the failure to effectively improve the safety of riders, who are considered the most vulnerable circulation

This work was supported in part by the Agence Nationale de la Recherche (ANR) in SIMulateur pour l'Apprentissage de la COnduite (SIMACOM).

$\mathrm{S}$. Espié is researcher with the Institut National de la Recherche sur les Transports et leurs Scurit (INRETS), 2 Avenue du General Malleret-Joinville F-94114 ARCUEIL Cedex, France.

H. Arioui, L. Nehaoua, S. Hima and N. Séguy are researchers with the IBISC CNRS FRE 3190 Laboratory at Evry Val d'Essonne University, 40 Rue du Pelvoux 91020 Evry Cedex, France. Email : hichem.arioui@ibisc.fr users because the result of accidents is far worse for cyclists than for other drivers [4], [5].

Driving on a two-wheeled vehicle is extremely different than driving a car. The differences result, primarily, from a motorcycle's dynamic aspects: equilibrium-stability, control and command, maneuverability, braking, and reaction time in the event of emergencies. The problem of visibility is also particularly critical for cyclists, especially at intersections or when overtaking. Most riders underestimate motorcycle dynamics and often ride at too great a speed, making it practically impossible to maintain control of the vehicle in dangerous or unforeseen situations. Motion cueing platforms constitute an effective simulation tool to perform various studies on a "vehicle" in a safe environment [6]. The goal of these is to reproduce driving situations, close to reality, in a restricted space to adequately excite the perceptual mechanisms of the human rider. The best known and most frequently used motion cueing algorithms are the classic, adaptive and optimal approaches [7], [8], [9].

Previously, few motorcycle riding simulators were built, since, researchers were more interested in flight and driving simulators. The first motorcycle simulator was conceived by Honda in 1988, and directed to the study of the stability and maneuverability of motorcycles [10]. The architecture was a serial mechanical-type with the possibility of movement based on five degrees of freedom (lateral, roll, pitch, yaw, and handlebar steering), movable by seven actuators. The motorcycle body was assembled on a cradle system in order to feed back the longitudinal accelerations. To control the simulation platform, a linear dynamic model of a motorcycle with 4 degrees of freedom (DOF) was used. It was found, however, that the driver could not control the simulator according to his intentions because the centrifugal force does not act like, and the roll acceleration characteristic differs from that of an actual motorcycle. Therefore, lateral acceleration differs from, that experienced in real riding. In addition, the concept of counter-steering experienced in actual riding has not been implemented, making the simulator uncontrollable.

After 1990, Honda built a second prototype with three DOF (roll, pitch, and direction) to allow the trainee to experience, in relative safety, hazardous situations in various traffic conditions on real city roads. This platform is controlled by an empirical motorcycle model which was validated by specialists in real-ride experiences [11]. More recently, Honda has commercialized a low-cost simulator with a six DOF parallel manipulator to plan the motion of the platform and a head-mounted display (HMD) for visual projection [12]. This prototype is intended to be used to train new motorcycle 
drivers.

In 1995, the PERCRO laboratory began a project, entitled the "MORIS Simulator". The goal of this project is to develop a tool for designers to learn about motorcycle handling and stability, as well as the rider's control behavior implications for motorcycle performances [13]. It consists of a real scooter mock-up mounted on a Stewart parallel platform with seven DOF (include a steering axis). The virtual motorcycle dynamic model has a one-DOF longitudinal motion for the speed calculation, which is used to solve the four DOF lateral dynamic models.

Finally, a motorcycle simulator prototype has been designed by the Mechanical Engineering Department at the University of Padua in order to study rider-vehicle interaction in safe conditions [14]. This interaction facilitated the development of a cyclist control model. The mechanical platform is a simple structure with five DOF (lateral, roll, pitch, yaw, and steering) and is actuated by five electric servomotors. All the driver commands are instrumented to be sent to the inputs of an eleven DOF, multi-body motorcycle model.

This paper is organized as follows. The next two sections discuss and deal with the movement choices and mechanical architecture of a new motorcycle riding simulation platform. These sections IV, V and VI provide theoretical studies on kinematics and dynamics modeling, and also address the identification process used here. Next, we present a description of the entire simulation loop and its various components. We end this paper with experimental results, preliminary conclusions, and suggestions for future works.

\section{Motivation Behind The MOVEMEnt CHOiCES}

The choices for the simulator architecture and movements are guided by the need to maintain sufficient perception while riding. In this sense, the objective of the simulator project is not to reproduce the motorcycle's every movement, but to reproduce the most significant inertial effects perceived by the human user for the expected applications.

After several investigations, it seems that, for the training and for the behavioral study of motorcycle-rider interaction, an adapted attitude, motion-generation mechanical platform is sufficient. The attitudes are selected as follows:

- Roll: for the reproduction of short cornering (slalom and directional change). In fact, the drive-in-curve (corner) crashes are one of the biggest causes of single-vehicle motorcycle accidents for new riders.

- Pitch: to create acceleration and braking illusion, as well as to reproduce fork ${ }^{1}$ movements.

- Yaw: to reproduce a close accident situation induced by the motorcycle's rear wheel skidding. A front wheel skid is purposely ignored as it is immediately fatal. In fact, the time between the stable and unstable states is extremely short in this case, when compared with a cyclist's response time. Therefore, to reproduce this

\footnotetext{
${ }^{1}$ On the motorcycle, the fork is the metal tubes that connect the front wheel to the motorcycle frame via the triple tree (the two-piece motorcycle part that attaches the fork tubes to the frame and makes steering possible). For handling, the front fork is a critical motorcycle component as it allows the rider to steer.
}

situation in order to learn any technique for control of the motorcycle by the rider is unnecessary, as it is impossible in the real situation.

The longitudinal and lateral displacements are also not retained, due to their expense, in this first prototype design. In addition, we know that the multiplication of perceptual stimuli can strongly increase riding simulation sensations [15]. Based on this idea, an original double haptic feedback system is implemented on the handlebar (described below). The first haptic system enables the simulation of the inertial delay on the rider's chest during the acceleration and braking phases, as well as exerting effort on the cyclist's arms by varying the distance between the saddle and the handlebar. The second feedback system attempts to reproduce, on the handlebar, the torque resulting from the tire-road interaction, as well as gyroscopic effects [16]. Additional details regarding the haptic feedback systems are provided in the next section.

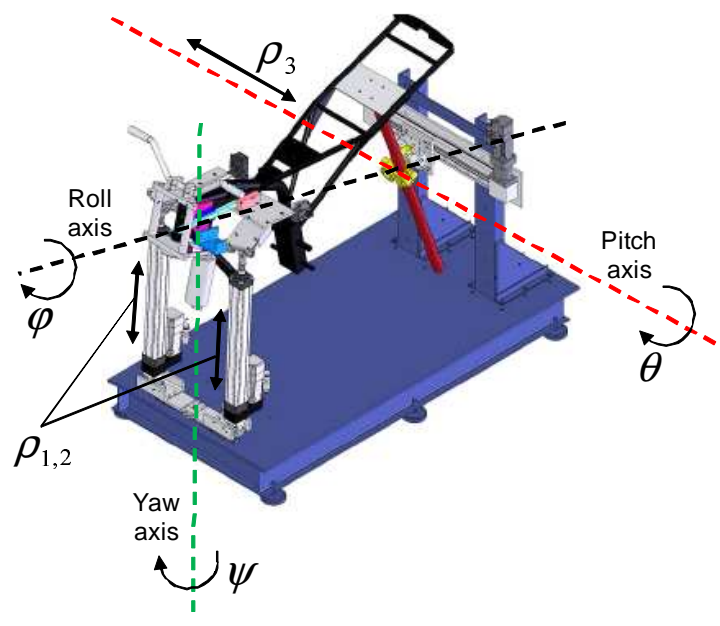

Fig. 1. CAD model of the simulator platform

The positioning of the rotation axes of the different movements is fundamental and directly affects the quality of perception. Unfortunately, there is no psychophysical assessment work in the literature to establish the influence of these choices (axes of rotation), except for simplistic cases [17]. Therefore, these axes are derived from real motorcycle kinematics [18]. In order to produce the necessary yaw and to feel the rear wheel skidding, a slide system is placed on the back of the motorcycle frame. The roll axis is placed in the motorcycle symmetry plane with an adjustable height in order to test various configurations and to achieve the best perception results. Lastly, for the pitch axis, it is the displacement of the front fork in the acceleration and braking phases which were privileged, therefore these axis passes by the back of the motorcycle frame. Figure 1 shows the CAD model of the platform simulator, which is described in the next section.

The present simulator has multiple advantages that differentiate it from existing simulators (in the literature few prototypes exist) :

- Type of movements to feed back, with a parallel structure which will increase the bandwidth mechanism. The present platform reproduces three important movements 
of motorcycle motions.

- A unique system for driver assistance, with double force feedback, used for the reproduction of the tire-road contact and to reproduce the longitudinal acceleration phases. This force feedback system is appreciated by all platform users.

- Low duplication cost for the prototype.

- The reproduction of the skidding of the rear wheel with an original structure. In the literature, this aspect has never been addressed.

\section{MECHANICAL DESIGN}

The motion cueing platform is composed of two metallic parts (upper and lower). The upper part is composed of the motorcycle chassis frame. The lower part consists of two metal structures. On the first one, all the platform components are assembled. The second structure is vertically mounted at the back of the horizontal structure with the slide drive system of the yaw motion affixed to it (Figure 2).

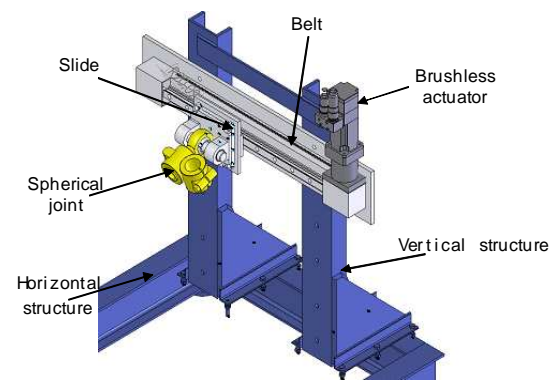

Fig. 2. The lower part, its two metallic frames and the yaw rear slide

To control the rolling and pitching motions of the motorcycle, two legs have been mounted in parallel between the lower metallic part and the motorcycle chassis frame (see Figure 3). The legs consist of two Electro-Thrusts incorporating a highquality ball screw drive. Each leg is connected, on one side, to the lower frame of the simulator by a cylindrical joint, and on the other side, to the motorcycle chassis by a spherical joint. The two Electro-Thrusts are driven by a brushless type servomotor.

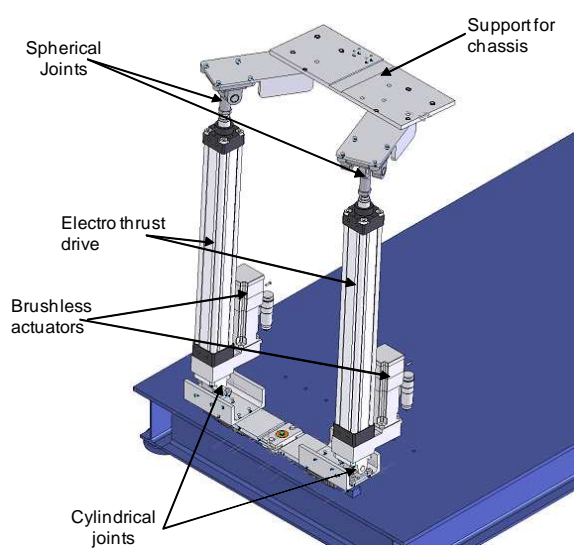

Fig. 3. The two front legs for pitch and roll motion
For the yaw motion, the machine is directly controlled by a slide system placed on the vertical structure. It is driven by a belt-actuated system, operated by a brushless servomotor, and reduction. The transmission of movement to the bike chassis is created by a steel bar rigidly attached to the rear of the motorcycle chassis frame from one side, and to the rear slide spherical joint from the other (see Figures 2 and 4).

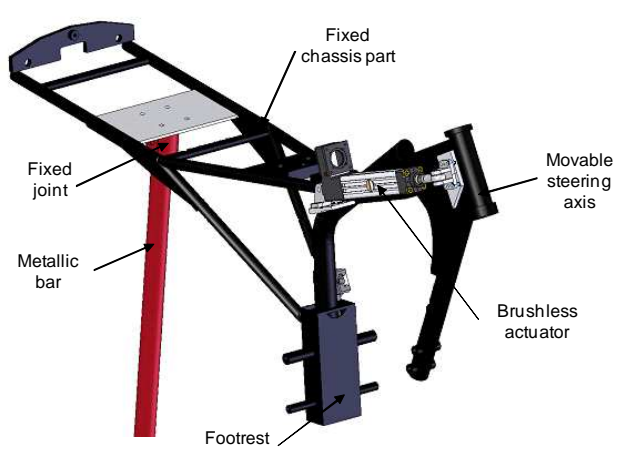

Fig. 4. The modified motorcycle chassis frame

Figure 5 illustrates the mechanism which maintains the distance unchanged between the two upper leg fixations when the platform performs a roll or yaw motion. This is realized by imposing a symmetric displacement of the two legs by means of a symmetrical double slider-crank system.

The mechanical portion of the upper platform is comprised of the motorcycle chassis (Figure 4). This last section consists of an adapted version of a real Yamaha YBR $125 \mathrm{~cm}^{3}$ mockup. As discussed previously, three supports are used to attach this mock-up to the front legs and rear slide bar. The original wheels and suspensions were removed to reduce the mass and inertia of the mock-up, and also because they have no use. Moreover, the main motorcycle commands (throttle, brake, clutch levers, and the gearbox selector) have been instrumented by adequate sensors to allow for the acquisition of rider's actions. The original mock-up dashboard is retained to provide visual feedback of motorcycle speed, engine mode, and all additional indicators.

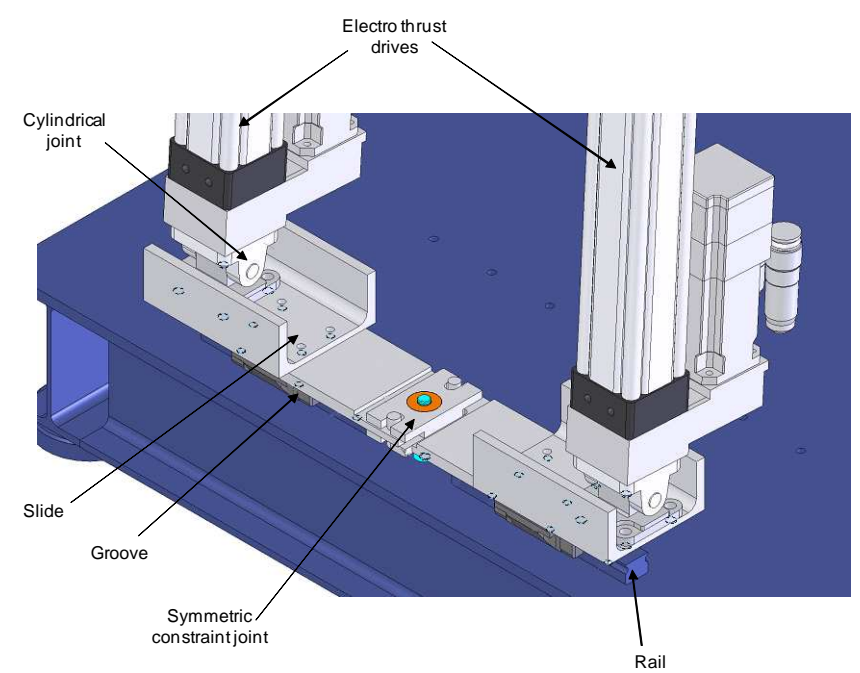

Fig. 5. The symmetrical double slider-crank system 
The steering axis of the motorcycle handlebar was disassembled from the original motorcycle chassis frame. The two forces applied through this system, to the rider, are connected by an Electro-Thrust leg, and driven by a brushless servomotor to control small displacements of the handlebar with respect to the motorcycle saddle; and consequently, exert a force on the rider's arms. Hence, this system can provide the rider an illusion during acceleration and braking phases.

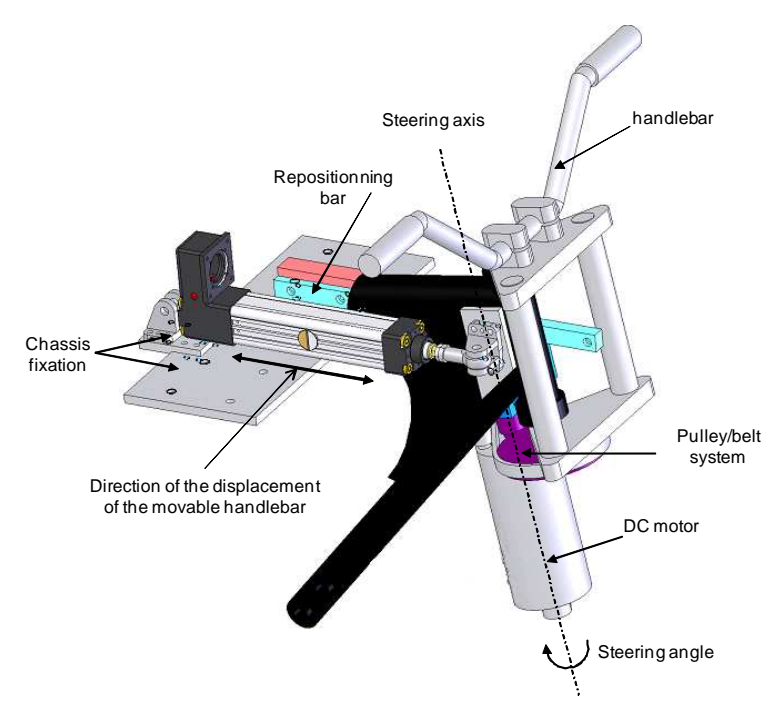

Fig. 6. The double haptic feedback system of the handlebar

When driving a real motorcycle, the rider is subjected to torque at the handlebar generated from the tire-road interaction which is transmitted through the steering column to the handlebar. This torque, known as self-aligning torque, is an important perception cue that significantly affects motorcycle riding behavior. Therefore, in order to reproduce the selfaligning torque on the simulator handlebar, a second haptic feedback system is integrated into the system to drive the steering rotation axis by way of a DC motor and pulley-belt assembly (see Figure 6).

\section{Platform Kinematics}

\section{A. Inverse kinematics formulation}

Inverse kinematics consists of defining the actuation joint coordinates, which are the leg elongations and the linear displacement of the rear slide, with respect to the Cartesian coordinates and orientation of the mobile platform. This section is of crucial importance in developing the dynamics model described in section $\mathrm{V}$.

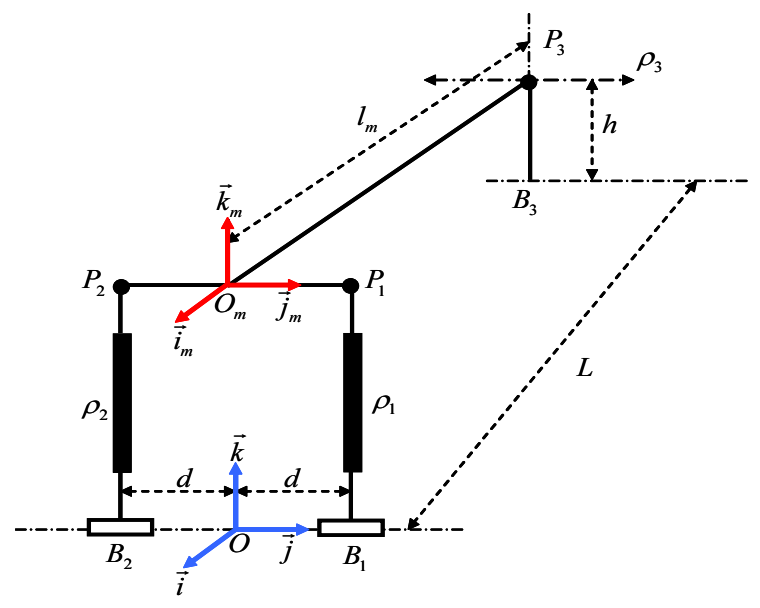

Fig. 7. Kinematics scheme of the simulator's platform

Let $\Re(O, \overline{\mathbf{i}}, \overline{\mathbf{j}}, \overline{\mathbf{k}})$ and $\Re_{m}\left(O_{m}, \overline{\mathbf{i}}_{\mathbf{m}}, \overline{\mathbf{j}}_{\mathbf{m}}, \overline{\mathbf{k}}_{\mathbf{m}}\right)$ be respectively the fixed, and the platform's mobile, references. $B_{1}, B_{2}$ and $B_{3}$ are, respectively, the attachment points of the two legs and the rear slide on the simulator's base. $P_{1}, P_{2}$ and $P_{3}$ are, respectively, the attachment points of the two legs and the rear slide on the upper mobile platform. The configuration of the reference frame $\Re_{m}$ is characterized by the position $\left(x_{m}, y_{m}, z_{m}\right)$ of its origin and three Euler orientation angles $(\psi, \theta, \varphi)$, corresponding respectively to yaw, pitch, and roll.

Taking the Z-Y-X convention, the rotation matrix is computed as follows:

$$
\mathcal{R}=\mathcal{R}_{\psi} \mathcal{R}_{\theta} \mathcal{R}_{\varphi}=\left(\begin{array}{lll}
r_{11} & r_{12} & r_{13} \\
r_{21} & r_{22} & r_{23} \\
r_{31} & r_{32} & r_{33}
\end{array}\right)
$$

or in a detailed form, where $c \equiv \cos$ and $s \equiv \sin$ :

$$
\mathcal{R}=\left(\begin{array}{ccc}
c \theta c \psi & s \varphi s \theta c \psi-c \varphi s \psi & c \varphi s \theta c \psi+s \varphi s \psi \\
c \theta s \psi & s \varphi s \theta s \psi+c \varphi c \psi & c \varphi s \theta s \psi-s \varphi c \psi \\
-s \theta & s \varphi c \theta & c \varphi c \theta
\end{array}\right)
$$

Vector $\overline{\mathbf{O P}}_{3}$ is given in the fixed base reference by $\overline{\mathbf{O P}}_{\mathbf{3}}{ }^{O}=\left(-L, \rho_{3}, h\right)^{T}$. Using the rotation matrix $\mathcal{R}$ the same vector can be written as:

$$
\overline{\mathbf{O P}}_{\mathbf{3}}{ }^{O}=\overline{\mathbf{O O}}_{\mathbf{m}}{ }^{O}+\mathcal{R} \overline{\mathbf{O}} \mathbf{m}_{\mathbf{3}}{ }^{m}
$$

where $\overline{\mathbf{O O}}_{\mathbf{m}}{ }^{O}=\left(x_{m}, y_{m}, z_{m}\right)^{T}$ and $\overline{\mathbf{O}} \mathbf{m}_{\mathbf{3}}{ }^{m}=$ $\left(-l_{m}, 0,0\right)^{T}$. By replacing the different vector components in equation (3) we can deduce the coordinates of the mobile reference origin, $O_{m}$, and the rear slide displacement, $\rho_{3}$, as follows:

$$
\left\{\begin{array}{l}
x_{m}=-L+l_{m} r_{11} \\
y_{m}=0 \\
z_{m}=h+l_{m} r_{31} \\
\rho_{3}=-l_{m} r_{21}
\end{array}\right.
$$

where $L, h$ and $l_{m}$ are geometric constants (Figure 7). Next, the leg vector equation for $i=1,2$ is given by:

$$
\overline{\mathbf{B}} \mathbf{i}_{\mathbf{i}}{ }^{O}={\overline{\mathbf{B}_{\mathbf{i}}}}^{O}+\overline{\mathbf{O O}}_{\mathbf{m}}{ }^{O}+\mathcal{R}{\overline{\mathbf{O}} \mathbf{m} \mathbf{P}_{\mathbf{i}}}^{m}
$$


where ${\overline{\mathbf{O}_{\mathbf{m}} \mathbf{P}_{\mathbf{i}}}}^{m}=l\left(0,(-1)^{i+1}, 0\right)^{T},{\overline{\mathbf{B}_{\mathbf{i}} \mathbf{O}}}^{O}=(-1)^{i} d \overline{\mathbf{j}}$ and $d$ is the coordinate of the two cylindrical joints $B_{1}$ and $B_{2}$. $l$ is the distance between $O_{m}$ and $P_{i}$. Substituting this into equation (5), the components of vectors, $\overline{\mathbf{B}}_{\mathbf{i}} \mathbf{P}_{\mathbf{i}}{ }^{O}=\rho_{i} \overline{\mathbf{u}}_{\mathbf{i}}$, can be deduced as follows:

$$
\rho_{i} \overline{\mathbf{u}}_{\mathbf{i}}=\left(\begin{array}{c}
-L+l_{m} r_{11}+(-1)^{i+1} l r_{12} \\
0 \\
h+l_{m} r_{31}+(-1)^{i+1} l r_{32}
\end{array}\right)
$$

and

$$
d=l r_{22}
$$

where $\overline{\mathbf{u}}_{\mathbf{i}}$ is the unit vector along the leg axis, and $\overline{\mathbf{j}}=$ $(0,1,0)^{T}$ and $\rho_{i}^{2}=\overline{\mathbf{B}}_{\mathbf{i}} \mathbf{P}_{\mathbf{i}}{ }^{T} \overline{\mathbf{B}}_{\mathbf{i}} \mathbf{P}_{\mathbf{i}}$ are the leg lengths.

To determine the inverse Jacobian matrix, we denote the Euler angle rates vector by $\dot{\overline{\mathbf{q}}}_{\mathbf{r}}=(\dot{\psi}, \dot{\theta}, \dot{\varphi})^{T}$. The velocity of the leg elongation is given by:

$$
\dot{\rho}_{i}={\dot{\mathbf{B}_{\mathbf{i}} \dot{\mathbf{P}}_{\mathbf{i}}^{T}}}_{\overline{\mathbf{u}} \mathbf{i}}
$$

Differentiating equation (5) and replacing it in (8) we find that:

$$
\dot{\rho}_{i}=(-1)^{i} \overline{\mathbf{u}}_{\mathbf{i}}^{T} \dot{d} \overline{\mathbf{j}}+\overline{\mathbf{u}}_{\mathbf{i}}^{T} \cdot \dot{\mathbf{O O}}_{\mathbf{m}}+\left(\Omega \times{\overline{\mathbf{O}} \mathbf{m} \mathbf{P}_{\mathbf{i}}}^{T} \overline{\mathbf{u}}_{\mathbf{i}}\right.
$$

where $\Omega=\mathcal{E} \dot{\overline{\mathbf{q}}}_{\mathrm{r}}$ is the mobile platform angular velocity expressed in the fixed reference frame, and $\mathcal{E}$ is the matrix transformation between the angular velocity and Euler angle rates. Equation (9) can be written by using the mixed vector product property, $(\overline{\mathbf{u}} \times \overline{\mathbf{v}}) \cdot \overline{\mathbf{w}}=(\overline{\mathbf{w}} \times \overline{\mathbf{u}}) \cdot \overline{\mathbf{v}}$, as follows:

$$
\dot{\rho}_{i}=(-1)^{i} \overline{\mathbf{u}}_{\mathbf{i}}^{T} \dot{d \mathbf{j}}+\overline{\mathbf{u}}_{\mathbf{i}}^{T} \cdot \dot{\mathbf{O O}}_{\mathbf{m}}+\left(\overline{\mathbf{u}_{\mathbf{i}}} \times{\overline{\mathbf{P}} \mathbf{i} \mathbf{O}_{\mathbf{m}}}_{{ }^{T} \Omega} \Omega\right.
$$

For the rear slide velocity, we have $\rho_{3}=\overline{\mathbf{j}}^{T} \overline{\mathbf{O P}}_{3}$. By differentiating and rearranging, we get:

$$
\dot{\rho}_{3}=\overline{\mathbf{j}}^{T} \dot{\mathbf{O O}}_{\mathbf{m}}+\left(\overline{\mathbf{j}} \times \overline{\mathbf{P}} \mathbf{3}_{\mathbf{\mathbf { O }}}^{\mathbf{m}}\right)^{T} \Omega
$$

From equations (10) and (11) and knowing that $\overline{\mathbf{u}}_{\mathbf{i}}^{T} \overline{\mathbf{j}}=0$, we can deduce that:

$$
\overline{\mathbf{V}}_{\rho}=\mathcal{J}_{-1} \overline{\mathbf{W}}
$$

where, $\overline{\mathbf{V}}_{\rho}=\left(\dot{\rho}_{1}, \dot{\rho}_{2}, \dot{\rho}_{3}\right)^{T}, \overline{\mathbf{W}}=\left(\dot{\mathbf{O O}}_{\mathbf{m}}{ }^{T}, \Omega^{T}\right)$ is the platform twist, and the inverse Jacobian matrix is:

$$
\mathcal{J}_{-1}=\left[\begin{array}{cc}
\overline{\mathbf{u}}_{\mathbf{1}}{ }^{T} & \left(\overline{\mathbf{u}}_{\mathbf{1}} \times{\left.\overline{\mathbf{P}} \mathbf{1} \mathbf{O}_{\mathbf{m}}\right)^{T}}_{\overline{\mathbf{u}}_{\mathbf{2}}{ }^{T}}\right. \\
\overline{\mathbf{j}}^{T} & \left(\overline{\mathbf{j}} \times{\left.\overline{\mathbf{P}} \mathbf{2} \mathbf{O}_{\mathbf{m}}\right)^{T}}_{\left.\mathbf{P}_{\mathbf{3}} \mathbf{O}_{\mathbf{m}}\right)^{T}}^{T}\right.
\end{array}\right]
$$

It is clear that this Jacobian matrix is a rectangular $(3 \times 6)$ matrix. The current mechanical platform has $3 \mathrm{DOF}$ and the six elements of the twist vector, $\overline{\mathbf{W}}$, are not independent. In fact, the elements of the vector, $\overline{\mathbf{O O}}_{\mathbf{m}}$, are directly related to the elements of the rotational vector, $\overline{\mathbf{q}}_{\mathbf{r}}=[\varphi, \theta, \psi]$. We can express that $\dot{\mathrm{OO}}_{\mathrm{m}}=\mathcal{A} \dot{\overline{\mathrm{q}}}_{\mathrm{r}}$, where $\mathcal{A}$ is easily obtained by differentiating equation (4). By replacing $\dot{\overline{O O}}_{m}$ and $\Omega$ with their expression in (12), we can deduce a more convenient $(3 \times 3)$ Jacobian matrix, $\mathcal{J}_{(m,-1)}$, as follow:

$$
\mathcal{J}_{(m,-1)}=\mathcal{J}_{-1}\left[\begin{array}{l}
\mathcal{A} \\
\mathcal{E}
\end{array}\right]
$$

Which is always invertible within the platform workspace (Table I), so there is no singularity.

\begin{tabular}{|c|c|c|c|}
\hline DOF & Roll & Pitch & Yaw \\
\hline Max rotation angle & $\pm 72^{\circ}$ & $\pm 10^{\circ}$ & $\pm 10^{\circ}$ \\
\hline Max angular velocity & $\pm 360^{\circ} / \mathrm{s}$ & $\pm 30^{\circ} / \mathrm{s}$ & $\pm 90^{\circ} / \mathrm{s}$ \\
\hline Motion axis & $\rho_{1}$ & $\rho_{2}$ & $\rho_{3}$ \\
\hline Max linear displacement & $\pm 0.20 \mathrm{~m}$ & $\pm 0.20 \mathrm{~m}$ & $\pm 0.18 \mathrm{~m}$ \\
\hline Max velocity displacement & $\pm 0.55 \mathrm{~m} / \mathrm{s}$ & $\pm 0.55 \mathrm{~m} / \mathrm{s}$ & $\pm 0.76 \mathrm{~m} / \mathrm{s}$ \\
\hline
\end{tabular}

TABLE I

MAXIMUM WORKSPACE AND VELOCITIES OF THE SiMUlatoR'S PLATFORM

\section{B. Forward kinematics formulation}

Forward kinematics consists of defining the Cartesian coordinates and orientation of the mobile platform with respect to the actuation joint coordinates. In our case, there are no angular sensors, so the forward kinematics is needed for control and identification tasks presented later.

Using $\mathcal{J}_{(m,-1)}$ expression (14), equation (12) can be rewritten as:

$$
\overline{\mathbf{V}}_{\rho}=\mathcal{J}_{(m,-1)} \dot{\overline{\mathbf{q}}}_{\mathbf{r}}
$$

For a small variation, equation (15) becomes:

$$
\Delta \overline{\mathbf{R}}_{\rho}=\mathcal{J}_{(m,-1)} \Delta \overline{\mathbf{q}}_{\mathbf{r}}
$$

where:

$\Delta \overline{\mathbf{R}}_{\rho}=\left(\Delta \rho_{1}, \Delta \rho_{2}, \Delta \rho_{3}\right)^{T}$ and $\Delta \overline{\mathbf{q}}_{\mathbf{r}}=(\Delta \psi, \Delta \theta, \Delta \varphi)^{T}$.

Equation (16) is the base of forward kinematics computation which is achieved by the following algorithm:

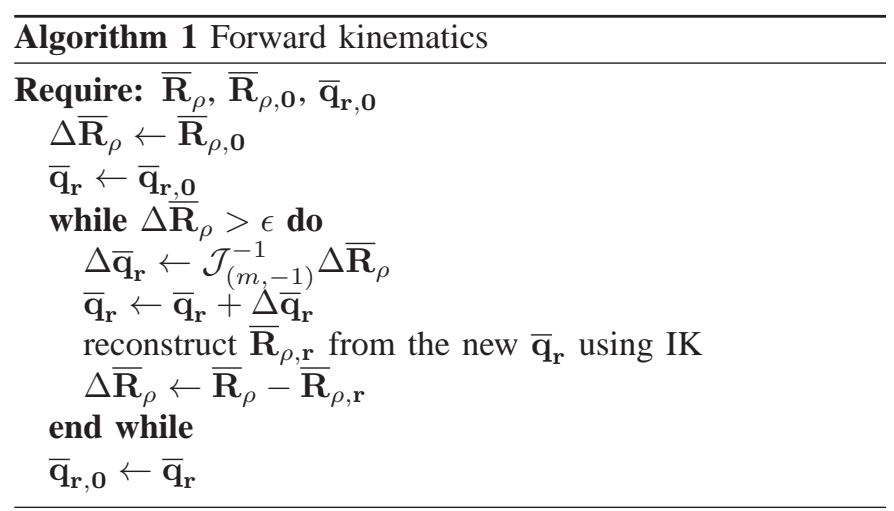

Here, $\overline{\mathbf{R}}_{\rho, \mathbf{r}}$ means the reconstructed joint coordinates and $\epsilon$ is the error between the input vector $\overline{\mathbf{R}}_{\rho}$ and the reconstructed one. Table I shows the platform workspace limits calculated from the exposed forward kinematics algorithm. 


\section{DYNAMICS OF THE PLATFORM}

In this section, a simple dynamics formulation of the simulator's platform will be demonstrated. The primary objective is to propose a control scheme adapted for our riding application and to characterize the platform's capabilities. For this, we neglect in the first instance the contribution of the leg dynamics and focus on the upper platform's motion. Application of Newton-Euler equations [19] on the mobile platform gives:

$$
\begin{aligned}
& m_{p} \overline{\mathbf{g}}+\overline{\mathbf{F}}_{\mathbf{1}}+\overline{\mathbf{F}}_{\mathbf{2}}+\overline{\mathbf{F}}_{\mathbf{3}}=m_{p} \overline{\mathbf{O G}}_{\mathbf{p}} \\
& m_{p} \overline{\mathbf{O}}_{\mathbf{m}} \mathbf{G}_{\mathbf{p}} \times \overline{\mathbf{g}}+{\overline{\mathbf{O}} \mathbf{m} \mathbf{P}_{\mathbf{1}}} \times \overline{\mathbf{F}}_{\mathbf{1}}+\overline{\mathbf{O}} \mathbf{m}_{\mathbf{2}} \times \overline{\mathbf{F}}_{\mathbf{2}}+ \\
& \overline{\mathbf{O}} \mathbf{m}_{\mathbf{P}} \mathbf{P}_{\mathbf{3}} \times \overline{\mathbf{F}}_{\mathbf{3}}=m_{p} \overline{\mathbf{O}}_{\mathbf{m}} \mathbf{G}_{\mathbf{p}} \times \overline{\mathbf{O G}}_{\mathbf{p}}+\Im_{p} \dot{\Omega}+\Omega \times \Im_{p} \Omega
\end{aligned}
$$

where $\overline{\mathbf{F}}_{\mathbf{i}}, i=1 . .3$ are the actuation and friction forces of the front two legs and rear slide. $m_{p}, \Im_{p}$ platform mass and inertia matrix. ${\overline{\mathbf{O}} \mathbf{m} \mathbf{G}_{\mathbf{p}}}_{\mathrm{s}}$ is the position of the mobile platform center of gravity $G_{p}$ with respect to point $O_{m}$. All vectors and matrices are expressed in the global reference frame $(O, \overline{\mathbf{i}}, \overline{\mathbf{j}}, \overline{\mathbf{k}}) . \Omega$ is the rotational velocity, expressed in the inverse kinematics section. Combining the two equations into one differential formulation yields:

$\mathcal{J}_{-1}^{T} \overline{\mathbf{F}}=m_{p}\left[\begin{array}{c}\frac{\mathcal{I}_{3}}{\mathbf{O}_{\mathbf{m}} \mathbf{G}_{p}}\end{array}\right]\left(\ddot{\mathbf{O G}}_{\mathbf{p}}-\overline{\mathbf{g}}\right)+\left[\begin{array}{c}\overline{\mathbf{0}}_{\mathbf{3} \times \mathbf{1}} \\ \Im_{p} \dot{\Omega}+\Omega \times \Im_{p} \Omega\end{array}\right]$

where $\mathcal{I}_{3}$ is $(3 \times 3)$ is the identity matrix, $\overline{\mathbf{0}}_{\mathbf{3} \times \mathbf{1}}$ is $(3 \times 1)$ is the vector of zeros, and $\overline{\mathbf{F}}=\left[\begin{array}{lll}F_{1} & F_{2} & F_{3}\end{array}\right]^{T} \cdot \overline{\mathbf{O G}}_{\mathbf{p}}$ is the acceleration of the platform center of gravity with respect to the global frame, given by:

$$
\ddot{\mathbf{O G}}_{\mathbf{p}}=\overline{\mathbf{O O}}_{\mathbf{m}}+\dot{\Omega} \times{\overline{\mathbf{O}_{\mathbf{m}} \mathbf{G}_{\mathbf{p}}}}+\Omega \times\left(\Omega \times{\overline{\mathbf{O}_{\mathbf{m}} \mathbf{G}_{\mathbf{p}}}}\right)
$$

Equation (19) can be written in a more convenient expression as:

$$
\widetilde{\mathbf{O G}}_{\mathbf{p}}=\left[\begin{array}{ll}
\mathcal{I}_{3} & -\widetilde{\mathbf{O}_{\mathbf{m}} \mathbf{G}_{\mathbf{p}}}
\end{array}\right] \dot{\overline{\mathbf{W}}}+\widetilde{\Omega}^{2}{\overline{\mathbf{O}_{\mathbf{m}} \mathbf{G}_{\mathbf{p}}}}
$$

where the following notation $\widetilde{\mathbf{x}}$ designates the skewsymmetric matrix of the vector $\overline{\mathbf{x}}$, that is $\overline{\mathbf{x}} \in \Re^{3}$ while $\widetilde{\mathbf{x}} \in \Re^{3 \times 3}$, given by:

$$
\widetilde{\mathbf{x}}=\left(\begin{array}{ccc}
0 & -x_{3} & x_{2} \\
x_{3} & 0 & -x_{1} \\
-x_{2} & x_{1} & 0
\end{array}\right)
$$

Replacing equation (20) into (18) and with various algebraic manipulations, we deduce the simplified dynamic model of the simulator's platform as:

$$
\mathcal{M} \dot{\overline{\mathbf{W}}}+\overline{\mathbf{C}}+\overline{\mathbf{G}}=\mathcal{J}_{-1}^{T} \overline{\mathbf{F}}
$$

where $\mathcal{M}$ is the mass matrix, $\overline{\mathbf{C}}$ is a nonlinear vector function of the angular velocity, and $\overline{\mathbf{G}}$ is the gravity term given as follows:

$$
\mathcal{M}=\left[\begin{array}{cc}
m_{p} \mathcal{I}_{3} & -m_{p} \widetilde{\mathbf{O}_{\mathbf{m}} \mathbf{G}_{\mathbf{p}}} \\
m_{p} \widetilde{\mathbf{O}_{\mathbf{m}} \mathbf{G}_{\mathbf{p}}} & \Im_{p}-m_{p} \widetilde{\mathbf{O}}_{\mathbf{m}} \mathbf{G}_{\mathbf{p}}
\end{array}\right]
$$

$$
\begin{aligned}
& \overline{\mathbf{C}}=\left[\begin{array}{c}
m_{p} \widetilde{\Omega}^{2} \overline{\mathbf{O}}_{\mathbf{m}} \mathbf{G}_{\mathbf{p}} \\
\widetilde{\Omega} \Im_{p} \Omega+m_{p} \mathbf{\mathbf { O } _ { \mathbf { m } } \mathbf { G }}{ }_{\mathbf{p}} \widetilde{\Omega}^{2}{\overline{\mathbf{O}_{\mathbf{m}} \mathbf{G}_{\mathbf{p}}}}
\end{array}\right] \\
& \overline{\mathbf{G}}=-m_{p}\left[\frac{\mathcal{I}_{3}}{\mathbf{O}_{\mathbf{m}} \mathbf{G}_{\mathbf{p}}}\right] \overline{\mathbf{g}}
\end{aligned}
$$

At this point, this model is capable of describing the dynamics of a fully actuated 6 DOF platform. Our architecture, however, is a 3 DOF model where the three rotations and three translations are dependent. Therefore, we must include three algebraic constraint equations. A simple formulation of Lagrange multipliers is added to the above model equation as:

$$
\mathcal{M} \dot{\overline{\mathbf{W}}}+\overline{\mathbf{C}}+\overline{\mathbf{G}}+\Phi_{q}^{T} \Lambda=\mathcal{J}_{-1}^{T} \overline{\mathbf{F}}
$$

where $\Lambda$ is the vector of Lagrange multipliers, $\Phi_{q}$ is the Jacobian of the constraint matrix $\Phi(q, t)=\overline{\mathbf{0}}$ such that $\dot{\Phi}(q, t)=\Phi_{q} \overline{\mathbf{W}}$. Owing to the symmetrical representation of the mechanical platform, the algebraic constraints can be deduced from the coordinates expression of the vector $\overline{\mathbf{O O}}_{\mathbf{m}}=\left(x_{m}, y_{m}, z_{m}\right)^{T}$, so:

$$
\Phi(q, t)=\left\{\begin{array}{l}
x_{m}+L-l_{3} c \theta c \psi-h_{3}(c \varphi s \theta c \psi+s \varphi s \psi)=0 \\
y_{m}=0 \\
z_{m}-h+l_{3} s \theta-h 3 c \varphi c \theta=0
\end{array}\right.
$$

Differentiation of $\overline{\mathbf{V}}_{\rho}=\mathcal{J}_{-1} \overline{\mathbf{W}}$ yields:

$$
\dot{\mathbf{W}}=-\mathcal{J}_{-1}^{-1} \dot{\mathcal{J}}_{-1} \mathcal{J}_{-1}^{-1} \overline{\mathbf{V}}_{\rho}+\mathcal{J}_{-1}^{-1} \dot{\overline{\mathbf{V}}}_{\rho}
$$

Replacing equation (28) into (26), we can deduce another representation, expressed in the actuation joint space, of the dynamics model such that:

$$
\mathcal{M}^{\prime} \dot{\mathbf{V}}_{\rho}+\overline{\mathbf{C}}^{\prime}+\overline{\mathbf{G}}^{\prime}=\mathcal{J}_{-1}^{T} \overline{\mathbf{F}}-\Phi_{q}^{T} \Lambda
$$

\section{IDENTIFICATION PROCESS}

The platform's parameter identification is of crucial importance in the control implementation and for the simulator's frequency characterization [20], [21]. Herein, we expose an identification procedure used to estimate the mass, inertia, and friction parameters. Generally, the dynamics model should be expressed in the local frame $\Re_{m}$, where the inertia matrix is constant. In the present work, however, we will continue with our previous formulation in the global frame, $\Re$, as we intend in future works to extend this identification procedure to a more complex model that will include the leg dynamics.

First, equation (26) must be written in a linear form with respect to the parameters being estimated. We should begin, however, by eliminating the vector of Lagrangian multipliers which represents the unknown, non-measurable, constraint forces. Thus, the twist vector $\overline{\mathbf{W}}$ is partitioned into two vectors of the independent velocities, $\dot{\overline{\mathbf{q}}}_{\mathbf{i}}$ and the dependent velocities, $\dot{\overline{\mathbf{q}}}_{\mathbf{d}}$. In the same way, the constraint Jacobian matrix is split accordingly to the partitioned vector $\overline{\mathbf{W}}$ as follows:

$$
\overline{\mathbf{W}}=\left[\begin{array}{c}
\dot{\overline{\mathrm{q}}}_{\mathrm{d}} \\
\dot{\overline{\mathrm{q}}}_{\mathbf{i}}
\end{array}\right] \text { and } \Phi_{q}=\left[\begin{array}{ll}
\mathcal{A}_{d} & \mathcal{A}_{i}
\end{array}\right]
$$


In addition to the above, by twice differentiating the constraint matrix $\Phi(q, t)=0$, we obtain that $\ddot{\Phi}(q, t)=\Phi_{q} \dot{\overline{\mathbf{W}}}+\Phi_{t}$, where $\Phi_{t}=\dot{\Phi}_{q} \overline{\mathbf{W}}$. Replacing $\overline{\mathbf{W}}$ and $\Phi_{q}$ by their expressions in the equation of $\ddot{\Phi}(q, t)$, we deduce the dependent acceleration vector from the independent vector as:

$$
\ddot{\overline{\mathbf{q}}}_{\mathbf{d}}=-\mathcal{A}_{d}^{-1}\left(\mathcal{A}_{i} \ddot{\overline{\mathbf{q}}}_{\mathbf{i}}-\Phi_{t}\right)
$$

Next, placing back this equation in the expression of the dynamics model in equation (26) allows us to eliminate the Lagrange multipliers vector. Therefore, by introducing the friction forces, the dynamics model equation becomes:

$$
\mathcal{B}_{m}^{T} \mathcal{M} \mathcal{B}_{m} \ddot{\overline{\mathbf{q}}}_{\mathbf{i}}+\mathcal{B}_{m}^{T}\left(\mathcal{M B}_{c}+\overline{\mathbf{C}}+\overline{\mathbf{G}}\right)=\mathcal{B}_{m}^{T} \mathcal{J}_{-1}^{T}\left(\overline{\mathbf{F}}-\overline{\mathbf{F}}_{\mathbf{f}}\right)
$$

where $\mathcal{B}_{m}$ is called the projection matrix given by $\mathcal{B}_{m}=$ $\left[-\left(\mathcal{A}_{d}^{-1} \mathcal{A}_{i}\right)^{T} \mathcal{I}_{3}\right]^{T}$ and $\mathcal{B}_{c}=\left[\left(\mathcal{A}_{d}^{-1} \Phi_{t}\right)^{T} \overline{\mathbf{0}}_{\mathbf{1} \times \mathbf{3}}\right]^{T}$. Finally, the dynamics model can be written in a linear formulation with respect to the vector, $\overline{\mathbf{p}}$, of the different parameters as follows:

$$
\Phi_{p} \overline{\mathbf{p}}=\mathcal{J}_{-1}^{T}\left(\overline{\mathbf{F}}-\overline{\mathbf{F}}_{\mathbf{f}}\right)
$$

Several methods were developed in the literature for the parametric identification. We chose the adaptive gradient method owing to its simplicity in off-line or on-line implementations. So, if $\tau=\mathcal{J}_{-1}^{T} \overline{\mathbf{F}}$, this method consists of optimizing a quadratic cost function $C_{f}=1 / 2\left(\tau_{\text {ref }}-\tau\right)^{2}$, where $\tau_{\text {ref }}$ relates to the measured actuation torques. The adaptation law is expressed as follows:

$$
\dot{\overline{\mathbf{p}}}=-\mathcal{K} \frac{\partial C_{f}}{\partial \overline{\mathbf{p}}}
$$

where $\mathcal{K}$ is the adaptation matrix coefficient, adjusted to ensure a rapid convergence, and also tied to the different excitation trajectories (slow or rapid reference trajectory). Finally, the different parameters are obtained by integrating the following equation:

$$
\dot{\overline{\mathbf{p}}}=\mathcal{K} \Phi_{p}^{T}\left(\tau_{r e f}-\Phi_{p} \overline{\mathbf{p}}-\mathcal{J}_{-1}^{T} \overline{\mathbf{F}}_{\mathbf{f}}\right)
$$

The identified parameters are summarized in the following table:

\begin{tabular}{|c|c|c|c|}
\hline Mass $m_{p}$ & Inertia $I_{1}$ & Inertia $I_{2}$ & Inertia $I_{3}$ \\
\hline $75.98 \mathrm{~kg}$ & $19.32 \mathrm{~kg} . \mathrm{m}^{2}$ & $4.69 \mathrm{~kg} . \mathrm{m}^{2}$ & $0.956 \mathrm{~kg} \cdot \mathrm{m}^{2}$ \\
\hline$X_{g}$ & $Y_{g}$ & $Z_{g}$ & Gravity center \\
\hline$-34.92 \mathrm{~cm}$ & $-1.07 \mathrm{~cm}$ & $-18.93 \mathrm{~cm}$ & Coordinates \\
\hline $\begin{array}{c}\text { Legs dry } \\
\text { friction }\end{array}$ & $\begin{array}{c}\text { Legs viscous } \\
\text { friction }\end{array}$ & $\begin{array}{c}\text { Slide dry } \\
\text { friction }\end{array}$ & $\begin{array}{c}\text { Slide viscous } \\
\text { friction }\end{array}$ \\
\hline 0.1738 N.m & 0.1425 N.s $/ \mathrm{m}$ & 0.0564 N.m & 0.0487 N.s $/ \mathrm{m}$ \\
\hline
\end{tabular}

TABLE II

FRICTION AND INERTIAL ESTIMATED PARAMETERS

\section{MEChatronics DESCRIPTION}

As depicted in Figure 8, the simulator software architecture is a revised version of the $\mathrm{SIM}^{2}$ car driving simulator [22] [23]. This software platform is organized by using two PCs interfaced by a UDP communication (User Datagram Protocol). The first PC, denoted XPC Target, is dedicated to the motorcycle dynamic calculation, trajectories generation and the real-time management of the acquired signals. The second $\mathrm{PC}$ is used for traffic determination, and the generation of the visual environment to be projected.

As depicted in Figure 8, all simulator modules are updated according to rider actions. These actions are measured and transmitted via the CAN bus to the virtual motorcycle dynamics. It allows the evaluation of the motorcycle's configuration (actual orientation and position) in the virtual world, and also the platform actuation with respect to the desired motions. However, due to platform workspace limitations, reference motions given by the virtual motorcycle dynamics are not necessarily achieved. Therefore, these trajectories are reshaped with a motion cueing algorithm [24], [25]. Then, the obtained quantities are transformed into joint coordinates using inverse kinematics in order to animate the mechanical structure.

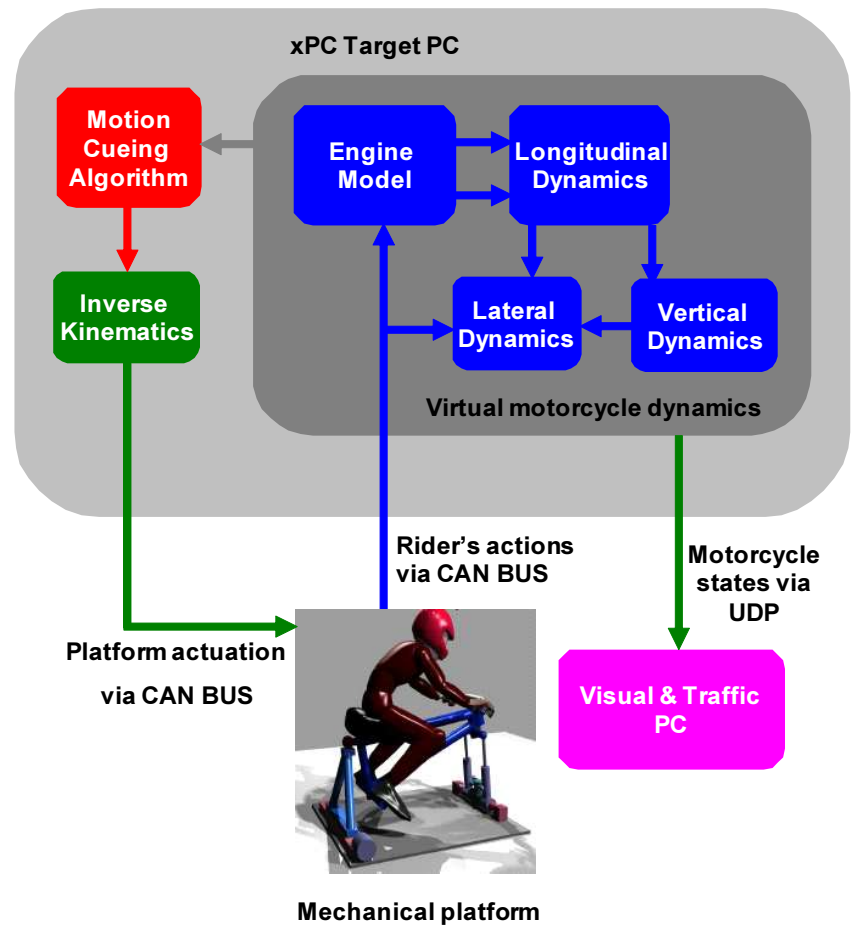

Fig. 8. Simulator software architecture

\section{A. Visual and traffic}

Inertial cues are essential to improving the driving simulation's quality. Nevertheless, the visual feedback received remains the most important driving information. For our simulator, the visual module was developed by INRETS MSIS is based on the SGI Performer Library.

The traffic model is intended to implement a realistic simulation of traffic situations which ensures rich interactivity in the projected visual scene. The traffic model used arises from results obtained throughout the ARCHISIM project, which has the primary goal of developing human-centered traffic simulations based on a real drivers' behavior with multi-agent concept implementations [26]. 
In [27] the authors have shown that depriving drivers of acoustic cues leads to a systematic increase in the speed of the vehicle. To prevent this issue from occurring, a 3D sound system based on Windows AEX Library is used. The reproduced sounds are mainly a juxtaposition of multiple sources with the primary sounds being the engine, tires, and traffic environment.

\section{B. Motorcycle dynamic model}

The motorcycle dynamic model is seen as the central part of the simulator architecture. Indeed, to animate the mechanical platform, it is necessary to generate the reference trajectories by updating the virtual motorcycle states in response to the rider's actions (throttle, brake and clutch levers and gearbox selector).

As shown in Figure 8, the virtual motorcycle model is decomposed on three decoupled motion modes. First, one DOF for longitudinal dynamics determines the longitudinal acceleration and traveling velocity from the driving torque, computed by the engine model, on the rear wheel as:

$$
\begin{aligned}
& -F_{t f} R_{f}-\tau_{b f}-M_{r f}=I_{w f} \ddot{\theta}_{w f} \\
& \tau_{d}-F_{t r} R_{r}-\tau_{b r}-M_{r r}=I_{w r} \ddot{\theta}_{w r} \\
& F_{t r}+F_{t f}-F_{a}-F_{g}=m a_{x}
\end{aligned}
$$

where: $F_{t f}, F_{t r}$ : the tractive force on the front and rear wheel, $R_{f}, R_{r}$ : front and rear wheel radius, $I_{w f}, I_{w r}$ : front and rear wheel inertia, $M_{r r}, M_{r f}$ : rolling resistance torques, $\tau_{b f}, \tau_{b r}$ : the brake torques, $F_{a}$ : aerodynamic force, $F_{g}$ : gravitational force due to the road slope and $\tau_{d}$ : the driving torque on the rear wheel as a function of the engine torque, clutch lever and transmission ratio.

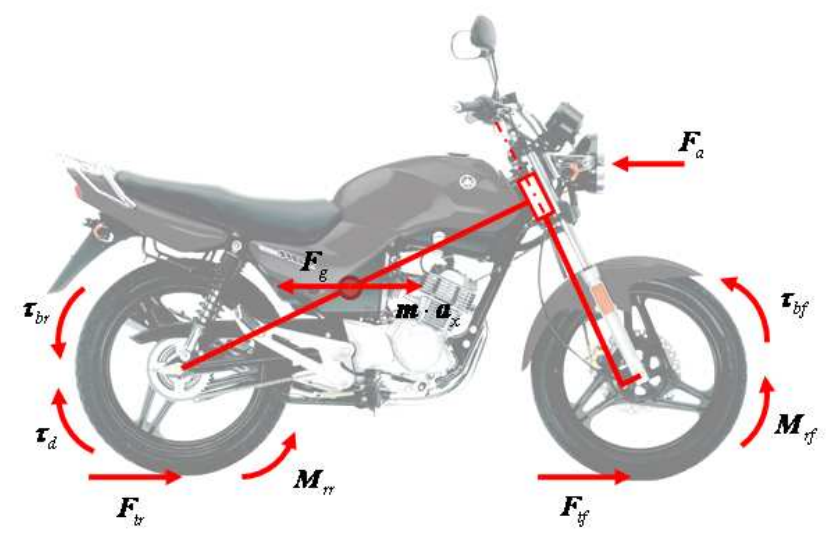

Fig. 9. Longitudinal motorcycle model

A 4 DOF linear-like equation for the lateral motion is also implemented as follows:

$$
A \dot{X}=B X+C U
$$

where $X=\left[\begin{array}{llllllll}v & \delta & \varphi & Y_{r} & Y_{f} & \dot{\psi} & \dot{\delta} & \dot{\varphi}\end{array}\right]^{T}$ is the states vector, $v$ : lateral velocity, $\delta, \varphi$ : steering and roll angles, $Y_{r}, Y_{f}$ : rear and front tire sliding force, $\dot{\psi}, \dot{\delta}$ and $\dot{\varphi}$ : yaw, steering and roll rates. $U$ : is the input vector which contains the exerted rider torque on the motorcycle handlebar (in our application, the human movements are neglected). For additional details on the equations model, please refer to [28].

\section{Acquisition electronics}

The simulator's mock-up is provided by all the riders' classical commands, which are equipped with adequate sensors (Table III).

\begin{tabular}{|c|c|c|}
\hline Signal & Sensor & Type \\
\hline \hline Throttle and clutch & Linear potentiometer & Analog \\
\hline Front and rear brake & Pressure & Analog \\
\hline Gearbox & Mechanical switch & Binary \\
\hline Steering angle & Optical coder & Binary \\
\hline
\end{tabular}

TABLE III

SENSOR LIST INSTALLED ON THE SIMULATOR'S MOCK-UP

The driver's signal acquisition is ensured by a homedesigned electronic card based on a V853 NEC microcontroller which disposes of the multiple analogue and digital inputs/outputs (Figure 10). It has the advantage of possessing an FPGA with several buffered binary inputs for optical encoders and signal acquisition. Moreover, the PWM (Power Wave Modulation) signal generation, intended to actuate the motorcycle handlebar, is included.

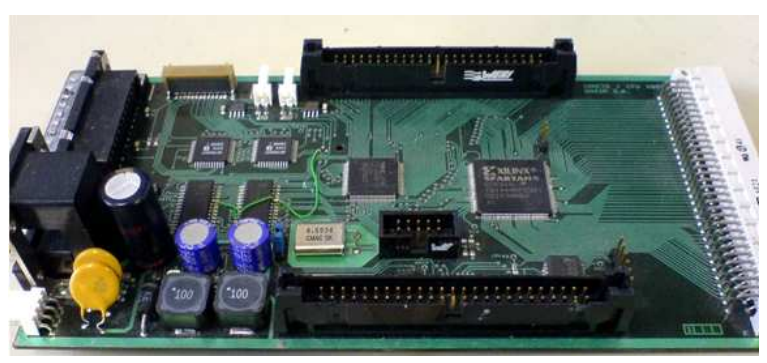

Fig. 10. Electronics acquisition card

\section{Platform actuation and control}

The 3 DOF of the mechanical platform and the displacement of the handlebar are electrically actuated by brushless motors (Table IV), each one driven by a servo-controller type "Lust CDD3000". The servo-controllers have multiple preconfigured presets, which define the type of the reference input signal and the regulation mode such as:

- Position, speed and torque control by an analogue $\pm 10 \mathrm{~V}$ reference input,

- Position and speed control: referenced and measured via a field bus (CAN BUS, Profibus, ...),

- Torque control via CAN BUS is not possible. 


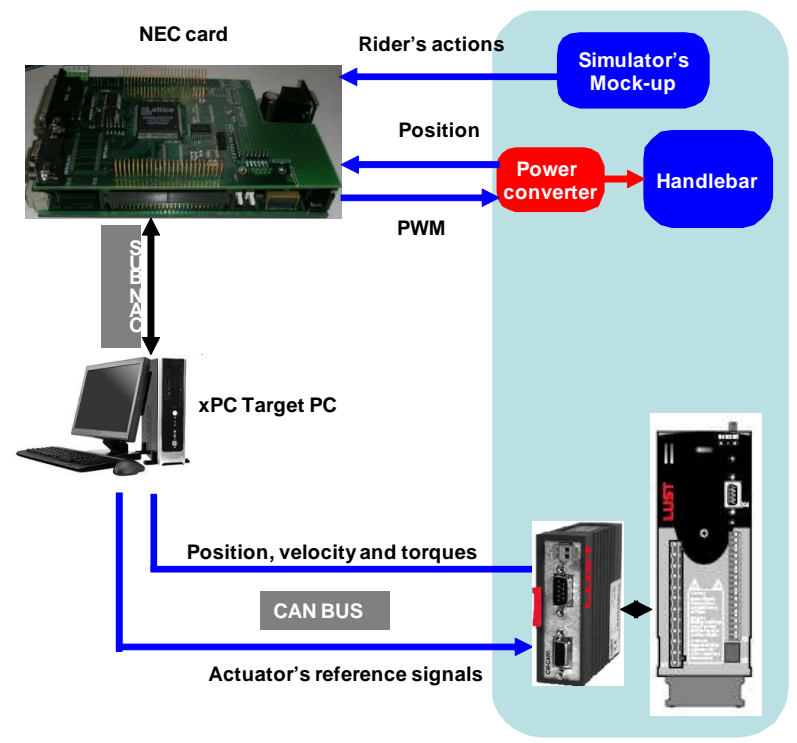

Fig. 11. Data actuation and acquisition scheme of the simulator's actuators and mock-up signals

Initially, all servo-controllers were driven in analogue mode, where the reference and measured signals were managed by the NEC micro-controller card. This mode, in particular, had affected the simulator's performance and had presented noise and delay problems. For our riding simulator application, such delays could create a serious problem and contribute to the generation of rider simulator sickness. To overcome these limitations, we have adopted a CAN BUS (Controller Area Network) solution scheme, which seems to be more robust against noises, reduces electrical cabling and wiring and facilitates task management and error diagnosis [29]. To achieve this, each servo-controller is supplied with a commercial CAN module type "LUST CM-CAN1" driven by a master CAN controller installed in the XPC target PC (Figure 11).

\begin{tabular}{|c|c|c|c|}
\hline Motion axis & Motor & Type & Reductor \\
\hline \hline front legs & SMBA6045 & brushless & Non \\
\hline rear slide & SMBA82300 & brushless & MP080 1:10 \\
\hline handlebar displacement & SMBA6045 & brushless & Non \\
\hline handlebar steering & RX320E & DC & Pully-belt 1:5 \\
\hline
\end{tabular}

TABLE IV

PLATFORM'S ACTUATOR LIST

On the other hand, we know that in a driving simulation, delay minimization is a more important characteristic than accurate trajectory tracking. In fact, the driving simulator aims to create the illusion of motion illusion and not to reproduce the full-scale motorcycle dynamics. For this, we have optimized the inner servo-controller control scheme without using an external control loop (Figure 12). Once the reference trajectories are computed by the xPC Target PC, they are forwarded via the CAN BUS to the corresponding servocontroller.

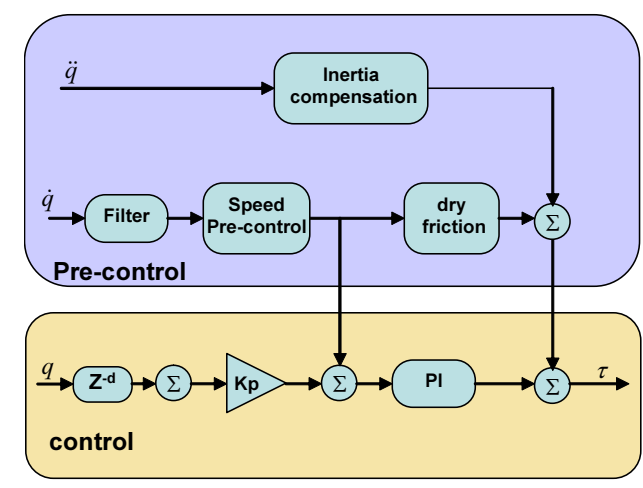

Fig. 12. Servo-controller inner control loops

Finally, a custom power converter is developed to drive the DC motor, which is implemented to provide force feedback to the handlebar.

\section{EXPERIMENTATION TESTS}

\section{A. Identification}

Identification of inertial parameters is based on equation (35). This expression shows that friction terms must be defined first. Thus, a simple method is used which consists of driving the simulator's platform with a step and ramp position profile (Figure 13). In addition, the dry and viscous friction models used here are respectively based on the Coulomb and Karnop formulations:

$$
\overline{\mathbf{F}}_{\mathbf{f}}=\overline{\mathbf{F}}_{\mathbf{f}, \mathbf{d}}+\overline{\mathbf{F}}_{\mathbf{f}, \mathbf{v}}=\mathcal{J}_{-1}^{-T} \tau_{d} \cdot \operatorname{sign}\left(\overline{\mathbf{V}}_{\rho}\right)+k_{v} \overline{\mathbf{V}}_{\rho}
$$

where $\overline{\mathbf{F}}_{\mathbf{f}, \mathbf{d}}$ and $\overline{\mathbf{F}}_{\mathbf{f}, \mathbf{v}}$ are, respectively, the dry and viscous friction forces in each actuator. $\tau_{d}$ and $k_{v}$ are the parameters to be identified. For a step position profile, speed and acceleration terms are canceled. Consequently, equation (32) becomes:

$$
\overline{\mathbf{F}}_{\mathbf{f}, \mathbf{d}}=\mathcal{J}_{-1}^{-T} \tau_{d} \cdot \operatorname{sign}\left(\overline{\mathbf{V}}_{\rho}\right)=\overline{\mathbf{F}}-\mathcal{J}_{-1}^{-T} \overline{\mathbf{G}}
$$

In the same manner, for a ramp position profile, the acceleration terms are canceled. Also, and by assuming that speed terms are negligible (low speed positioning), then:

$$
\overline{\mathbf{F}}_{\mathbf{f}, \mathbf{v}}=k_{v} \overline{\mathbf{V}}_{\rho}=\overline{\mathbf{F}}-\overline{\mathbf{F}}_{\mathbf{f}, \mathbf{d}}-\mathcal{J}_{-1}^{T} \overline{\mathbf{G}}
$$

Once the friction forces are determined, inertial parameters are identified by activating the simulator's platform with a wobble sinus position trajectory (Figure 14). Positions and torques are acquired by a CAN BUS at $100 \mathrm{~Hz}$ rate, while accelerations are obtained by numerical differentiation. Euler angles, $\overline{\mathbf{q}}_{\mathbf{r}}=[\psi, \theta, \varphi]^{T}$, needed for the constraint Jacobian and the Jacobian matrices, are computed by forward kinematics. 

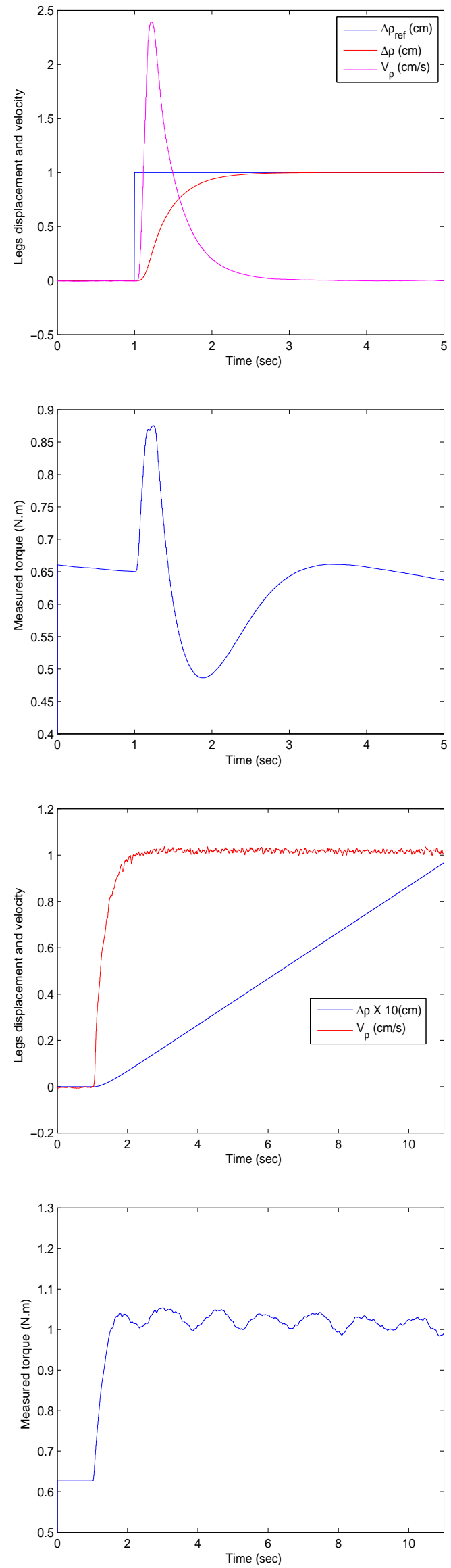

Fig. 13. Legs position, velocity and the corresponding measured torques used for friction terms estimation
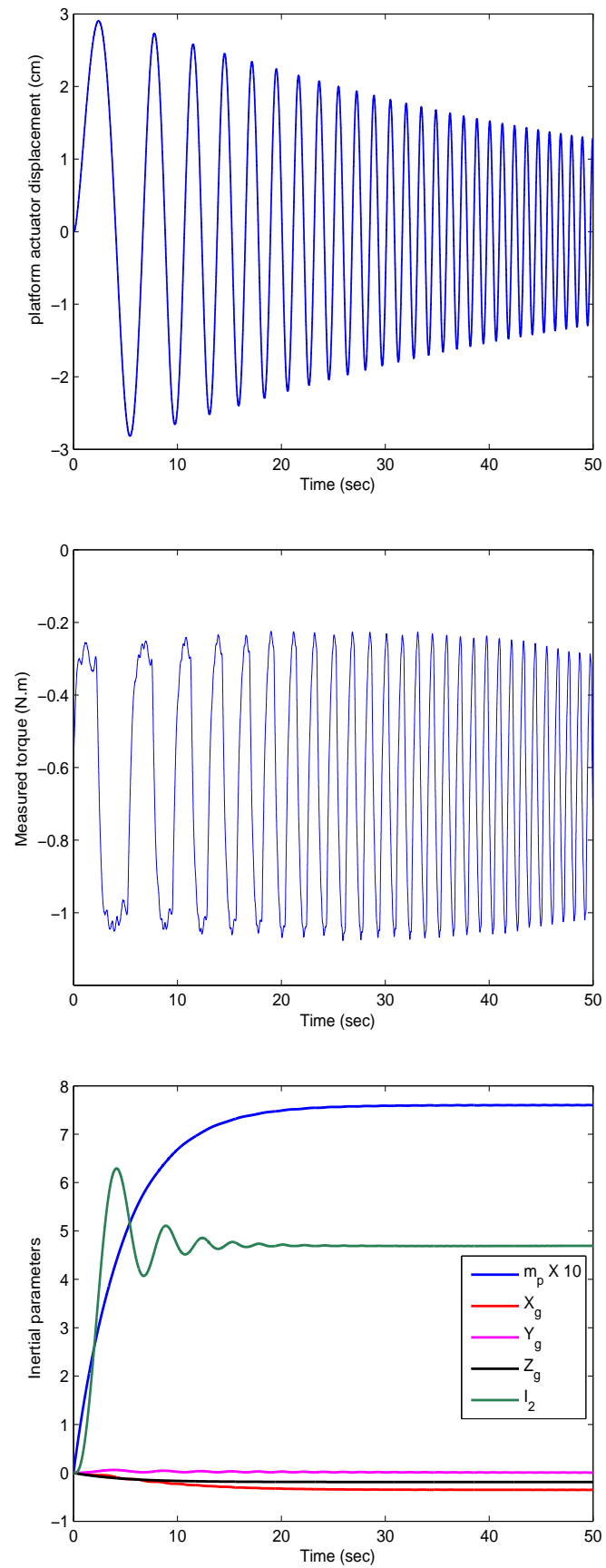

Fig. 14. Simulator's platform position, measured torque, and inertial parameters

\section{B. Performance validation tests}

In order to validate the actuation performances of the simulator's platform (Figure 15), several tests, in open-loop mode (without a cyclist's actions), were performed.

An example of $\pm 15^{\circ}$ roll and yaw maneuver is executed on the simulator platform with a rider of $80 \mathrm{~kg}$. Figures (16 and 17) show respectively the measured actuator torque and linear velocity of one of the two legs and the rear slide. We can see that the actuation system has the necessary ability to achieve the desired maneuver in the imposed simulator workspace. 
Indeed, for the roll simulation maneuver, the two front legs lead to an acceleration/deceleration close to $3 \mathrm{~m} / \mathrm{s}^{2}$ far from actuators' limits of $6 \mathrm{~m} / \mathrm{s}^{2}$. We can then conclude that the leg's actuator performances which need sufficient perception can be reached.

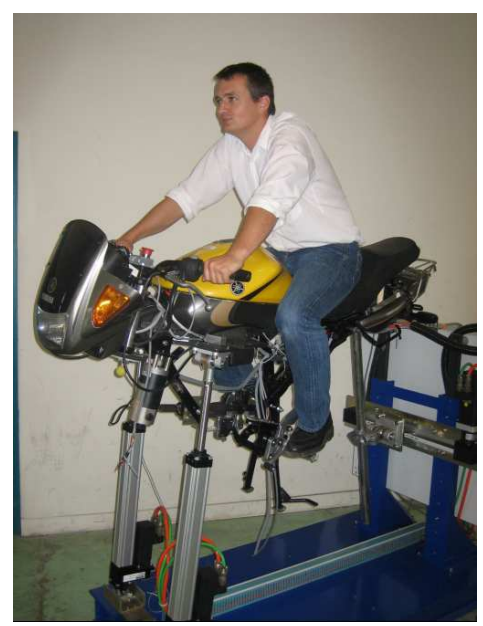

Fig. 15. Constructed riding motorcycle simulator

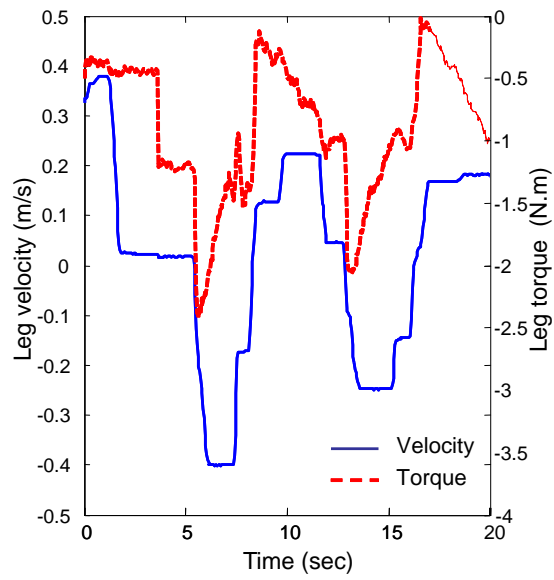

Fig. 16. Measured actuator torque and linear leg velocity for a $\pm 15^{\circ}$ roll motion

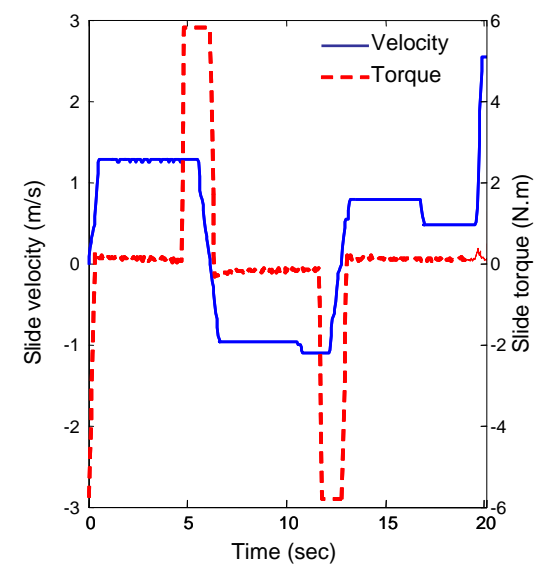

Fig. 17. Measured actuator torque and linear velocity of the rear slide for a $\pm 15^{\circ}$ yaw motion

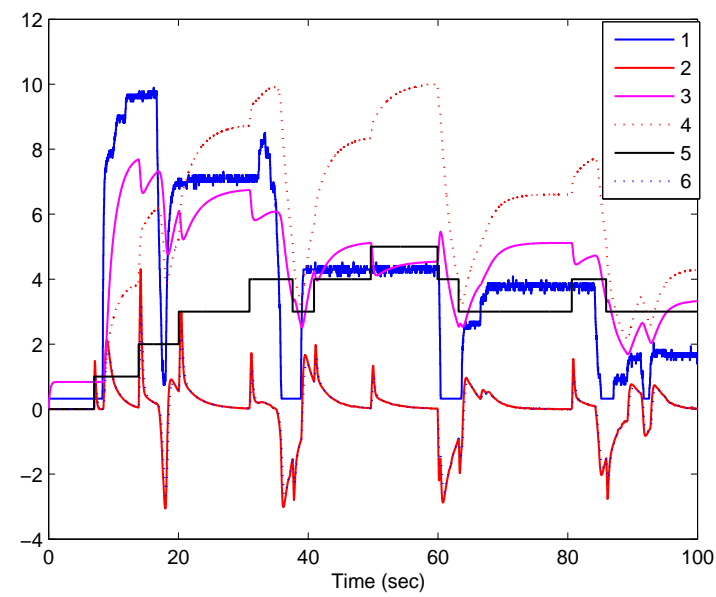

Fig. 18. 1: Throttle $(\times 10 \%)$, 2: Longitudinal acceleration $\left(\mathrm{m} / \mathrm{s}^{2}\right), 3$ : Engine $(\times 1000 \mathrm{rpm}), 4$ : Longitudinal speed $(\mathrm{m} / \mathrm{s}), 5$ : Gearbox report, 6: Pitch angle $\left({ }^{\circ}\right)$

For the yaw movement simulating a rear wheel skid, the corresponding actuator has delivered a torque close to $6 \mathrm{~N} . \mathrm{m}$ leading to a yaw motion estimated to be sufficiently perceived by the rider. Thus, the rear slide actuator is estimated as overdimensioned (35N.m of maximum torque). These remarks constitute a global evaluation of the whole system and allow us to conclude that the actuator's performance is appropriate its intended application.

\section{Open-loop tests}

In the following, we present the first open-loop tests. These experiments involve an evaluation of the response of all the simulator blocks (Figure 8) for three basic maneuvers, namely the driving-in-the-straight-line case, lane-changing, and driving in a curve, without introducing the driver to the simulation loop.

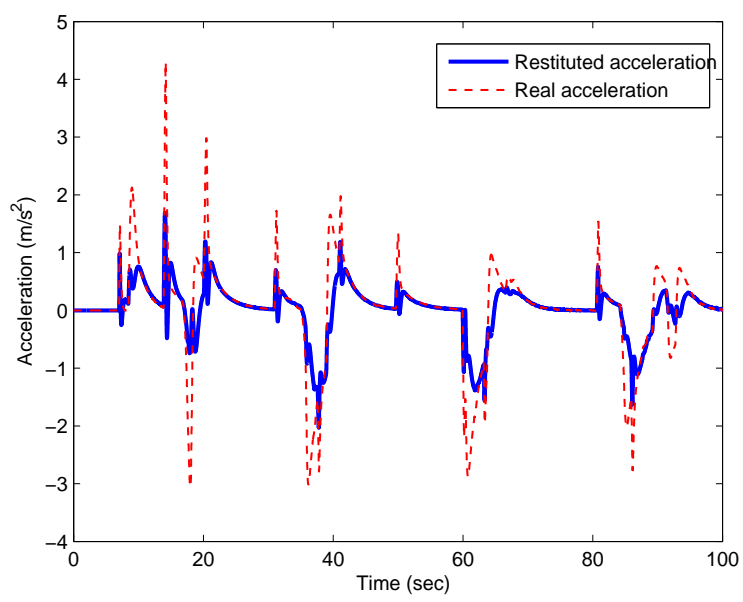

Fig. 19. Drive in straight-line: actual motorcycle acceleration and the experimental acceleration returned via the simulator

1) Drive in straight line case: This case is the basis of the vehicle platooning drive, implemented mainly in an urban 
traffic environment. This is a major undertaking, even for linear platforms conducted with a large displacement.

In this experiment, the various actions of the driver are used to calculate the longitudinal acceleration and speed of the virtual motorcycle (Figure 18). Figure 19 shows the actual acceleration as calculated by the virtual model of the motorcycle and the one simulated by the platform. Nevertheless, this graphic depiction provides an indication of the feasibility of this platform to render a longitudinal acceleration. Only closed-loop tests, i.e. driver in the simulation loop, are able to validate the relevance of these results.

2) Lane-changing and driving in curve: These maneuvers are essential for assessing the ability of the simulator to reproduce part of the lateral dynamic that occur during motorcycle driving. In these tests, a PD controller for driving the virtual motorcycle model, to determine the driver torque $\tau$, is needed. Indeed, any curvilinear trajectory is characterized by its radius, from which the roll angle $\varphi_{d}$, which is necessary to maintain the stability of the bike, is determined in constant longitudinal speed. This formula is provided below as :

$$
\tau=K_{p}\left(\varphi_{d}-\varphi\right)+K_{d} \dot{\varphi}
$$
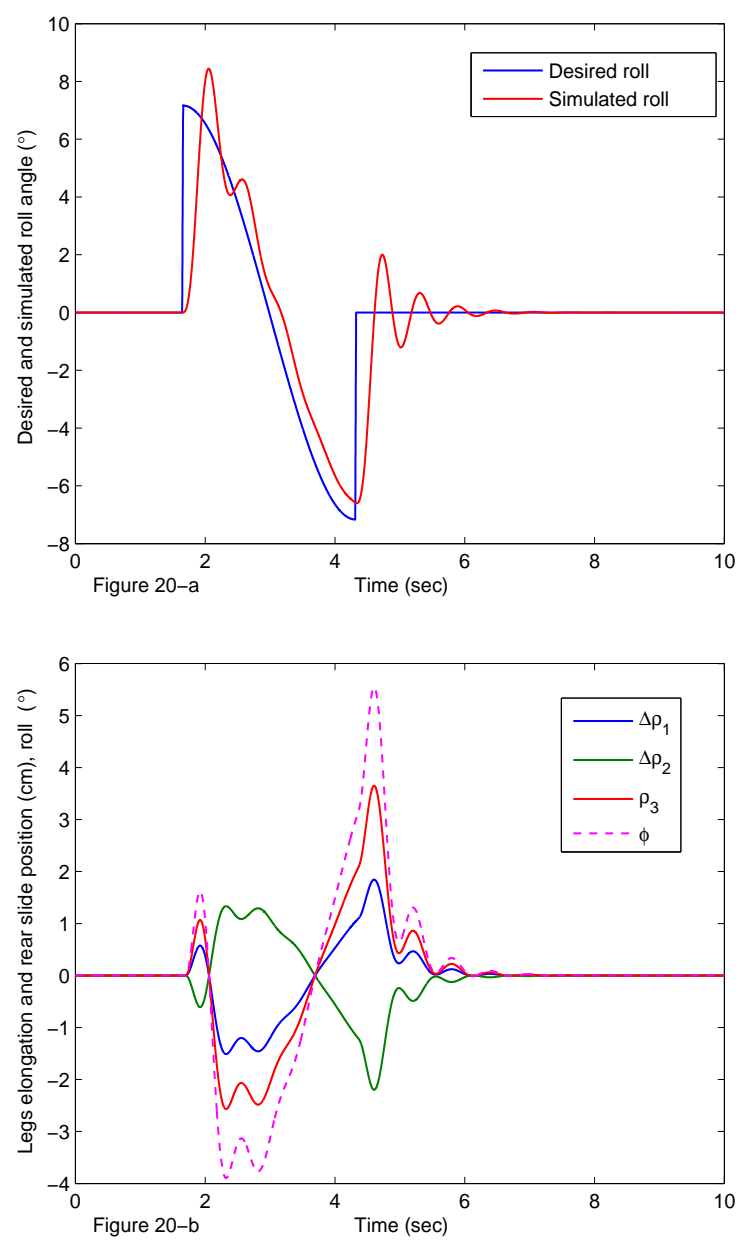

Fig. 20. Lane-changing: (a) Desired and simulated roll angles given by the virtual motorcycle model, (b) Front legs elongation $\Delta \rho_{1}, \Delta \rho_{2}$, Rear slide position $\rho_{3}$ and Simulator roll angle $\varphi_{s}$

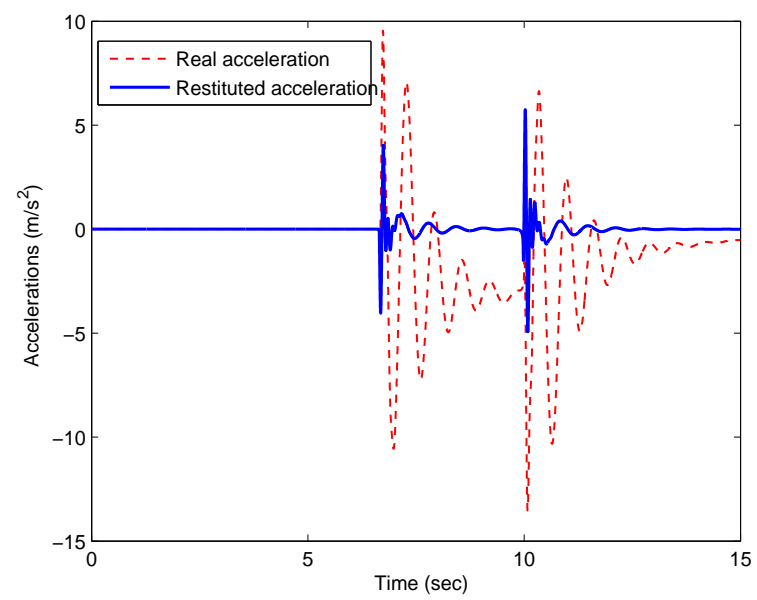

Fig. 21. Drive in curve: motorcycle acceleration and the experimental acceleration returned via the simulator
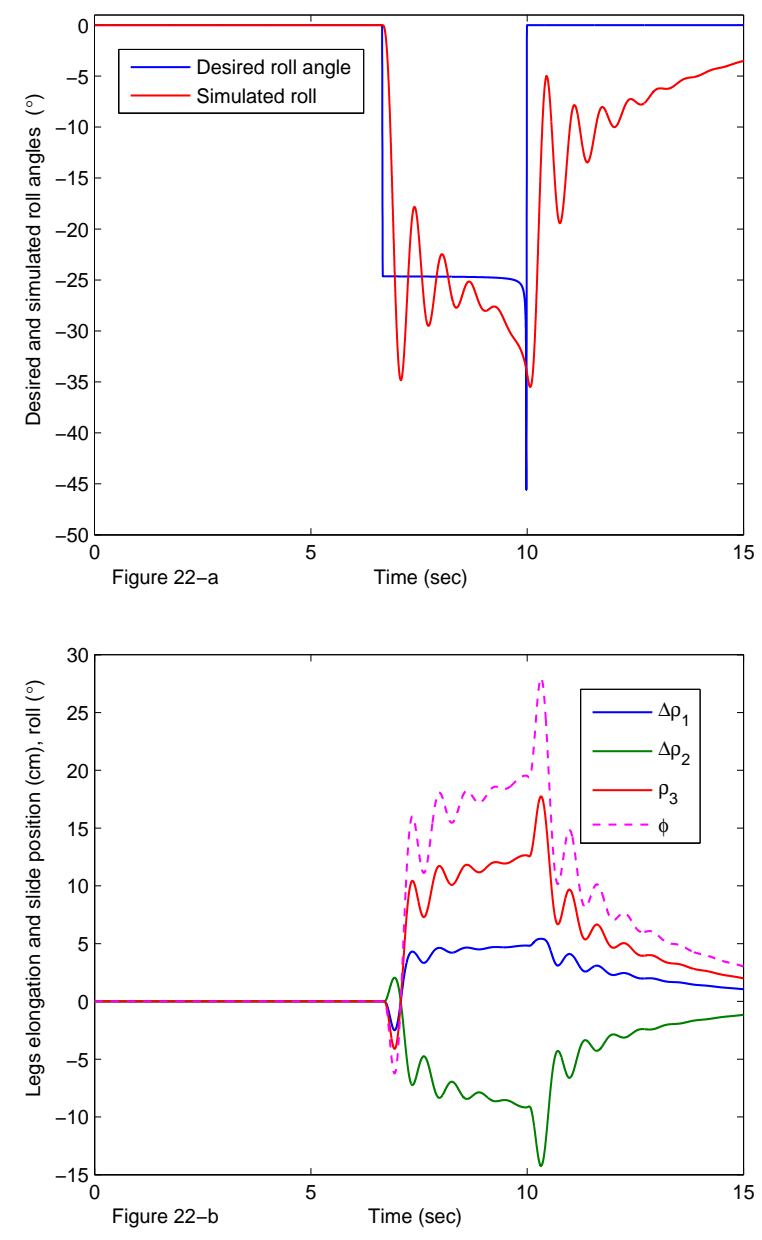

Fig. 22. Drive in curve : (a) Desired and simulated roll angle, (b) Front legs elongation $\Delta \rho_{1}, \Delta \rho_{2}$, Rear slide position $\rho_{3}$ and Simulator roll angle $\varphi_{s}$

Figures 20 and 21 illustrate the different parameters required in lane-changing maneuvers. The trajectory is approximately $4 \mathrm{~m}$ in width and $20 \mathrm{~m}$ in length with a longitudinal speed of $15 \mathrm{~m} / \mathrm{s}$. In a similar manner, Figures 22 and 23 depict the same variables for a turn-taking maneuver with a radius of 
$50 \mathrm{~m}$. This experiment is performed under the same conditions in term of longitudinal speed.

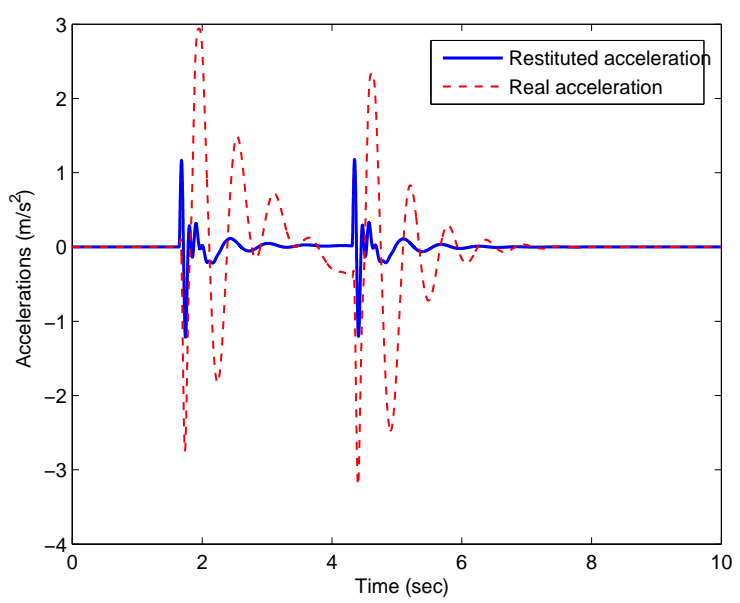

Fig. 23. Lanes changing : motorcycle acceleration and the experimental acceleration returned via the simulator

\section{CONCLUSION AND FUtURE WORKS}

In this paper, we present a low-cost, two-wheeled riding simulator that provides acceptable motion and realism. The application to which this simulator is dedicated and the necessary perceptions have guided us to propose an original mechanical architecture.

The platform has five DOF. Two of the five DOF are dedicated to the force feedback on the handlebars. The modeling and control of these DOF have not been addressed in this paper and will be treated separately. The remaining 3 DOF concern the rotation motions realized on the platform. Several motivations were implemented in an original mechanical system, presented in detail.

Kinematics, dynamics and identification studies were carried out, allowing optimal control of the platform. The simulator software architecture part, including traffic and dynamic model of the motorcycle, are illustrated.

Multiple open-loop tests were performed satisfactorily and permitted us to meet our objectives for urban situations (platooning, lane changing and driving in curves). This judgment, however, is made from a control perspective. For a complete validation, psychophysical evaluations are necessary in order to answer the remaining questions on such issues as the washout location, produced movement fidelity, and realism of the riding simulation.

Concerning low-cost justification, existing motorcycle driving simulators, with same (or more) mobility of our structure, use generally Gough- Stewart parallel platforms which are excessively expensive. Comparison of perception quality between these structures is to be studied regarding to psychophysical tests.

Future works are foreseen which will focus on tests utilizing a closed-loop simulation, including a rider on the simulator. A more complex motorcycle model will be validated by collecting real data recorded in real riding situations and integrated into the simulation loop. The double kinesthetic feedback on the handlebar is soon to be integrated to the suited motion restitution algorithms. Moreover, the present simulator will be placed on the $\mathrm{SIM}^{2}$ driving simulator platform to explore both longitudinal and lateral DOF affects on linear acceleration restitution during a riding simulation.

After testing the proposed motorcycle platform simulator, the necessary improvements will be completed according to feedback opinions from psychophysics evaluators, users and professional riders and researchers. Multiple design iterations may be necessary to realize a final prototype that will reach its initial goals in terms of perception quality.

\section{ACKNOWLEDGMENT}

This research was supported by funds from the NATIONAL ReseARCH AGENCY in Simacom Framework. Many thanks to Seddik Djouadi and Michael Regan for there kind review of the document.

\section{REFERENCES}

[1] S. F. Schmidt and B. Conrad, "Motion drive signals for piloted flight simulators," in Contractor Report NASA CR-1601, Washington, USA, 1970.

[2] A. Kemeny, "Simulation et perception du mouvement," in Driving Simulation Conference(DSC99), Paris, France, Jul. 1999, pp. 33-55.

[3] Les motocyclettes et la sécurité routiére en France en 2003. La documentation Francaise, Observatoire National Interministriel de Sécurité Routiére, ISBN: 2-11-005951-6, 2005.

[4] S. Evangelou, D. J. N. Limebeer, R. S. Sharp, and M. C. Smith, "Steering compensation for high-performance motorcycles," IEEE Conference on Decision and Control, vol. 1, pp. 749-754, 2004.

[5] F. Forouhar and A. Packard, "Robust stabilization of high speed oscillations in single track vehicles," IEEE American Control Conference, vol. 1, pp. 26-30, 1994.

[6] S. Brennan and A. AlleyneE, "The illinois roadway simulator : A mechatronic testbed for vehicle dynamics and control," IEEE/ASME Transactions on Mechatronics, vol. 5, no. 4, pp. 349-359, 2000.

[7] R. V. Parrish, J. E. Dieudonne, R. L. Bowles, and D. J. Martin, "Coordinated adaptive washout for motion simulators," Journal of Aircraft, vol. 12, pp. 44-50, Jul. 1975.

[8] R. Sivan, J. Ish-shalom, and J. . Huang., "An optimal control approach to the design of moving flight simulators," IEEE Transactions on Systems, Man and Cybernetic, vol. 12, pp. 818-827, Jul.-Aug. 1982.

[9] P. R. Grant and L. D. Reid, "Motion washout filter tuning: Rules and requirements," Journal Of Aircraft, vol. 34, pp. 145-151, Mar.-Apr. 1997.

[10] Y. Miyamaru, G. Yamasaki, and K. Aoki, "Development of a motorcycle riding simulator," Society of Automotive Engineers of Japan, vol. 23, pp. 121-126, 2002.

[11] T. Katayama, "A simulation model for riders control behavior," Society of Automotive Engineers of Japan, no. 961, 1996.

[12] S. Chiyoda, K. Yoshimoto, D. Kawasaki, Y. Murakami, and T. Sugimoto, "Development of a motorcycle simulator using parallel manipulator and head mounted display," in Driving Simulation Conference(DSC00), Paris,France, 2000.

[13] D. Ferrazzin, F. Barnagli, C. Avizzano, G. Pietro, and M. Bergamasco, "Designing new commercial motorcycles through a highly reconfigurable virtual reality-based simulator," Journal of Advanced Robotics, vol. 17, no. 4, pp. 293-318, 2003.

[14] V. Cossalter, A. Doria, and R. Lot, "Development and validation of a motorcycle riding simulator," in World Automotive Congress(FISITA2004), Barcelona, Spain, May 2004.

[15] J. Neimer, H. Mohellebi, S. Espié, and A. Kheddar, "Optimization of linear motion base dedicated to normal driving conditions," in Driving Simulator Conference (DSC05), Orlando, Florida, 30 nov-2 dec 2005.

[16] H. Mohellebi, S. Espié, and A. Kheddar, "Adaptive haptic steering wheel for driving simulators," in Proceedings of 2004 IEEE/RSJ International Conference on Robots and Intelligent Systems (IROSO4), Jun. 2004.

[17] G. Yamasaki, K. Aoki, Y. Miyamaru, and K. Ohnuma, "Development of motorcycle training simulator," Society of Automotive Engineers of Japan, vol. 19, pp. 81-85, 1998. 
[18] V. Cossalter, Motorcycle Dynamics. Milwaukee, USA: Race Dynamics Inc, ISBN: 0-9720514-0-6, 2002.

[19] B. Dasgupta and T. Mruthyunjaya, "Closed-form dynamic equations of the general stewart platform through the newton-euler approach," Mech. Mach.Theory, vol. 33, pp. 993-1012, 1998.

[20] Y. Li and Q. Xu, "Design and development of a medical parallel robot for cardiopulmonary resuscitation," IEEE/ASME Transactions on Mechatronics, vol. 12, no. 3, pp. 265-273, 2007.

[21] L. Wang, J. Wu, J. Wang, and Z. You, "An experimental study of a redundantly actuated parallel manipulator for a 5-dof hybrid machine tool," IEEE/ASME Transactions on Mechatronics, vol. 14, pp. 72-81, Feb. 2009.

[22] H. Mohellebi, S. Espié, H. Arioui, A. Amouri, and A. Kheddar, "Low cost motion platform for driving simulator," in 5th International Conference on Machine Automation (ICMA04), Osaka, Japan, Nov. 2004.

[23] L. Nehaoua, A. Amouri, and H.Arioui, "Classic and Adaptive Washout Comparaison for a Low Cost Driving Simulator," in Proceedings of the 13th Mediterranean Conference on Control and Automation (MED05), Limassol, Cyprus, Jun. 2005, pp. 586-591.

[24] L. Nehaoua, H. Arioui, H. Mohellebi, and S. Espié, "Motion Cueing Algorithms for Small Driving Simulator," in Proceedings 2006 IEEE International Conference On Robotics and Automation (ICRA06), Orlando, Florida, May 2006, pp. 3189-3194.

[25] L. Nehaoua, H. Mohellebi, A. Amouri, H. Arioui, and A. Kheddar, "Design and control of a small-clearance driving simulator," IEEE Transactions on Vehicular Technology, vol. 57, no. 2, pp. 736-746, 2008.

[26] S. Espie, "Vehicle-driven simulator versus traffic-driven simulator: the inrets approach-driving simulation conference," in Driving Simulation Conference (DSC99), Paris, France, 1999.

[27] F. Panerai and al, "Speed and safety distance control in truck driving: comparison of simulation and real-world environment," Proceedings of driving simulation conference, pp. 91-107, 2001.

[28] R. Sharp, "Vibrational modes of motorcycles and their design parameter sensitivities," in Vehicle NVH and Refinement, Mechanical Engineering Publications, London, England, 1994, pp. 107-121.

[29] S. Donecker, T. Lasky, and B. Ravani, "A mechatronic sensing system for vehicle guidance and control," IEEE/ASME Transactions on Mechatronics, vol. 8, no. 4, pp. 500-510, 2003.

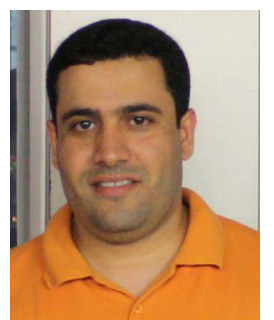

Hichem Arioui received the B.S. degree in engineering on control and automation systems science from Badji Mokhtar University, Annaba, Algeria, in 1998 and the M.S and Ph.D degree in robotics and automation from Evry University, France, in 1999 and 2002 respectively. He worked at Laboratoire d'Informatique, Biologie Intégrative et Systèmes Complexes (IBISC, University of Evry) on the control of haptic display under varying time delay in the frame of his PhD thesis. Since 2003, he is an associate professor of Electrical Engineering at the same University. His research interest includes modeling and control of haptic interaction and more recently design and control of driving simulator applications.

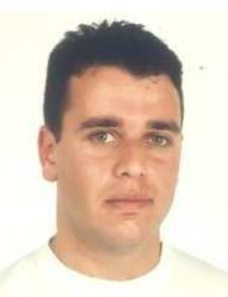

Lamri Nehaoua received the B.S. degree in engineering on control and automation systems science from the University of Sétif, Algeria, in 1999 and the M.S degree in computer vision for robotics application from Clermont-Ferrand II University, France, in 2002. He obtained his $\mathrm{PhD}$ degree from the Université d'Evry Val d'Essonne (UEVE) in 2008. $\mathrm{He}$ is currently at post-doctoral position in Laboratoire d'Informatique, Biologie Intgrative et Systmes Complexes (IBISC, UEVE). His main interest is simulators, modeling and control aspects.

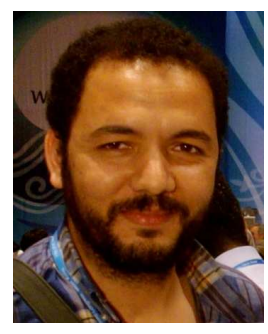

Salim Hima received the B.S. degree in electrical engineering from Farhat-Abbas University, Sétif, Algeria in 1996, DEA (Master of research) degree in autonomous robotics from the University of Paris VI in 2000 and $\mathrm{PhD}$ degree from the Université d'Evry Val d'Essonne(UEVE) in 2005. From 2006 to 2008 , he occupied a post-doctoral position in Laboratoire d'Informatique, Biologie Intgrative et Systèmes Complexes (IBISC) of the UEVE. Since 2009, he integrates Vehicle-Infrastructure-Driver interaction Laboratory (LCPC/INRETS) at Versailles, French, as an engineer of research. His research interests include robotics, control, trajectory planning for autonomous aerial vehicles, driving simulator and recently highly automated vehicles.

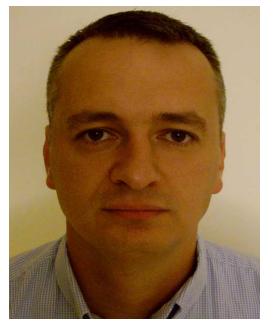

Nicolas Séguy received the B.S. Degree in mechanics in 1995, the M.S. Degree in robotics in 1997 both from University Paris 6, Paris, France and the $\mathrm{Ph} . \mathrm{D}$. degree in mechanics from Université d'Evry - Val d'Essonne, Evry, France, in 2003. Since 2004, he is an Associate Professor at Université d'EvryVal d'Essonne - IBISC laboratory. His research interest is mechanical modelling for human-in-theloop applications such as haptics and particularly driving simulators.

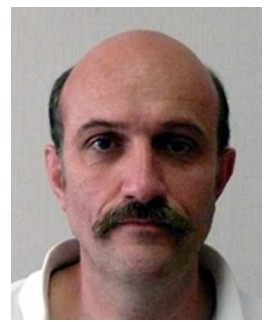

Stéphane Espié is a researcher, he holds an accreditation to direct research (HdR). He has been working at INRETS since 1982, first on new sensors for traffic, then on traffic simulation and on driving simulators. He is involved in the INRETS ITS works. $\mathrm{He}$ is currently involved in the French National Research and Development Project (ANR/PREDIT) , SIMACOM (2 wheels driving simulator for training of emergency manoeuvres), PREVENSOR (ITS and MMI), VIGISIM (driving simulator for studies of impact on driving of sleep deprivation, medics...), DAMOTO (towards an early detection of motorcycles falling) and also in the E.C. 6th framework INTRO (impact of weather conditions on road traffic), TRAIN-ALL (training tools and curriculum), and in the E.C. 7th framework SAFERIDER (ADAS, IVIS for motorcycles), 2BESAFE (motorcyclists behaviour) and PREDRIVE C2X (simulation of traffic systems including car to car and car to ground communications. He is the leader of SIMACOM, VIGISIM, DAMOTO and 2BESAFE projects. Main research areas are: Design of architecture dealing with both behavioural traffic simulation, driving simulator, distributed Artificial Intelligence, artificial life, co-operative systems. 